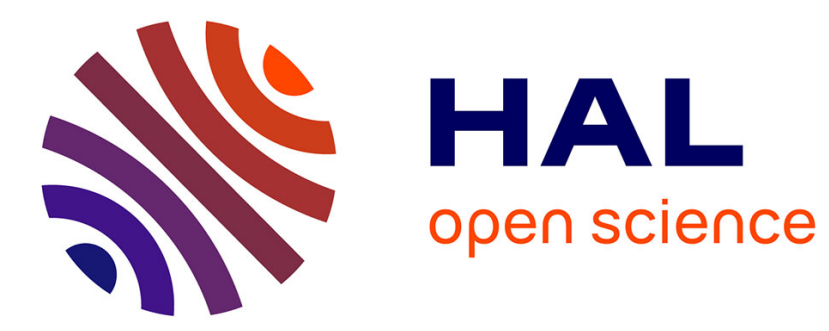

\title{
La tête en tôle de bronze de Genainville (Val d'Oise)
}

Pierre-Henri Mitard

\section{To cite this version:}

Pierre-Henri Mitard. La tête en tôle de bronze de Genainville (Val d'Oise). Gallia - Fouilles et monuments archéologiques en France métropolitaine, 1982, 40 (1), pp.1-33. 10.3406/galia.1982.1851. hal-01940262

\section{HAL Id: hal-01940262 \\ https://hal.science/hal-01940262}

Submitted on 27 Feb 2020

HAL is a multi-disciplinary open access archive for the deposit and dissemination of scientific research documents, whether they are published or not. The documents may come from teaching and research institutions in France or abroad, or from public or private research centers.
L'archive ouverte pluridisciplinaire HAL, est destinée au dépôt et à la diffusion de documents scientifiques de niveau recherche, publiés ou non, émanant des établissements d'enseignement et de recherche français ou étrangers, des laboratoires publics ou privés.

\section{(이) $\$$}

Distributed under a Creative Commons Attribution - NonCommercial - NoDerivatives $\mid 4.0$ 


\title{
LA TÊTE EN TÔLE DE BRONZE DE GENAINVILLE (Val-d'Oise)
}

\author{
par Pierre-Henri MITARD
}

Le site gallo-romain de Genainville (Val-d'Oise), lieu-dit Les Vaux de la Celle, rassemble au fond d'un vallon un thèatre (devant lequel devait s'étendre un forum), un temple flanqué au sud d'une série de bassins et quelques bàtiments secondaires; les thermes qui devaient compléter cet ensemble n'ont pas été retrouvés jusqu'ici'. Il s'agit certainement d'un de ces lieux de rassemblements temporaires des populations rurales d'une région - ici partie du territoire des Véliocasses -... dont les autorités romaines ont facilité le développement, d'un conciliabulum, si l'ont veut retenir l'expression que propose de leur appliquer M. ('. Ch. Picard ${ }^{2}$. L'origine du site réside dans la présence d'une source, auprès de laquelle devaient se réunir les Gaulois dès l'époque de l'Indépendance et qui a été aménagée en nymphée avec bassins annexes à l'époque romaine. Les monuments principaux (temple et théâtre), richement ornés de sculptures, sont datables du milieu ou du troisième quart du I $^{\mathbf{e}}$ siècle, mais des vestiges de constructions antérieures (peut-ître du début du ier siècle) ont été découverts à l'emplacement du temple et de ses abords ${ }^{3}$. Les principaux monuments du site ont fortement souffert de l'invasion barbare de 275-276.

Le bâtiment où a été découverte (en mai 1979) la tête humaine en tòle de bronze, objet de cette étude, dit Bàtiment secondaire VIII, se situe à $7,50 \mathrm{~m}$ au nord de l'angle n.-e. du temple, au pied du còteau nord et très probablement à proximité de l'emplacement initial de la source, captée pour alimenter les bassins. Le bâtiment se réduit maintenant a un radier de fondations rectangulaire, de $7,30 \times 5,45 \mathrm{~m}$ (petits côtés au sud et au nord)

1 Voir sur ce site notre article de présentation génerale paru dans Forum, revue du Groupe archéologie antiqque du Touring-Club de France, no 2, 1972 (p. 20-28), ainsi que les Informalions archéologiques de la Région parisienne, puis d'Ile de France, dans Gallia, XIX, 1961, p. 293 ; XXI, 1963, p. 349 ; XXIII, 1965, p. 304 ; XXV, 1967, p. 219; XXVIII, 1970, p. $246 ; 30,1972$, p. $309 ; 33,1975$, p. $327 ; 35,1977$, p. $329 ; 37,1979$, p. 345 . Voir aussi les Informations archéologiquess régionales du Bulletin archéologique du Vexin français, t. 1, 1965 à 12/13, 1976/1977 (1979) et $15,1979(1981$ :

2 C'est dailleurs la denomination quavait appliquée des 1949 au site de (ienainville M. G. Matherat, alors directeur des Antiquités historiques de la Kégion parisienne (Gallia, VI1, 1949, p. 111).

3 In petit cimetiere datable du ve s. avant notre ère fin Hallstatt-debut de Ia Téne; a dautre part été découvert sur le site à l'est du temple. 


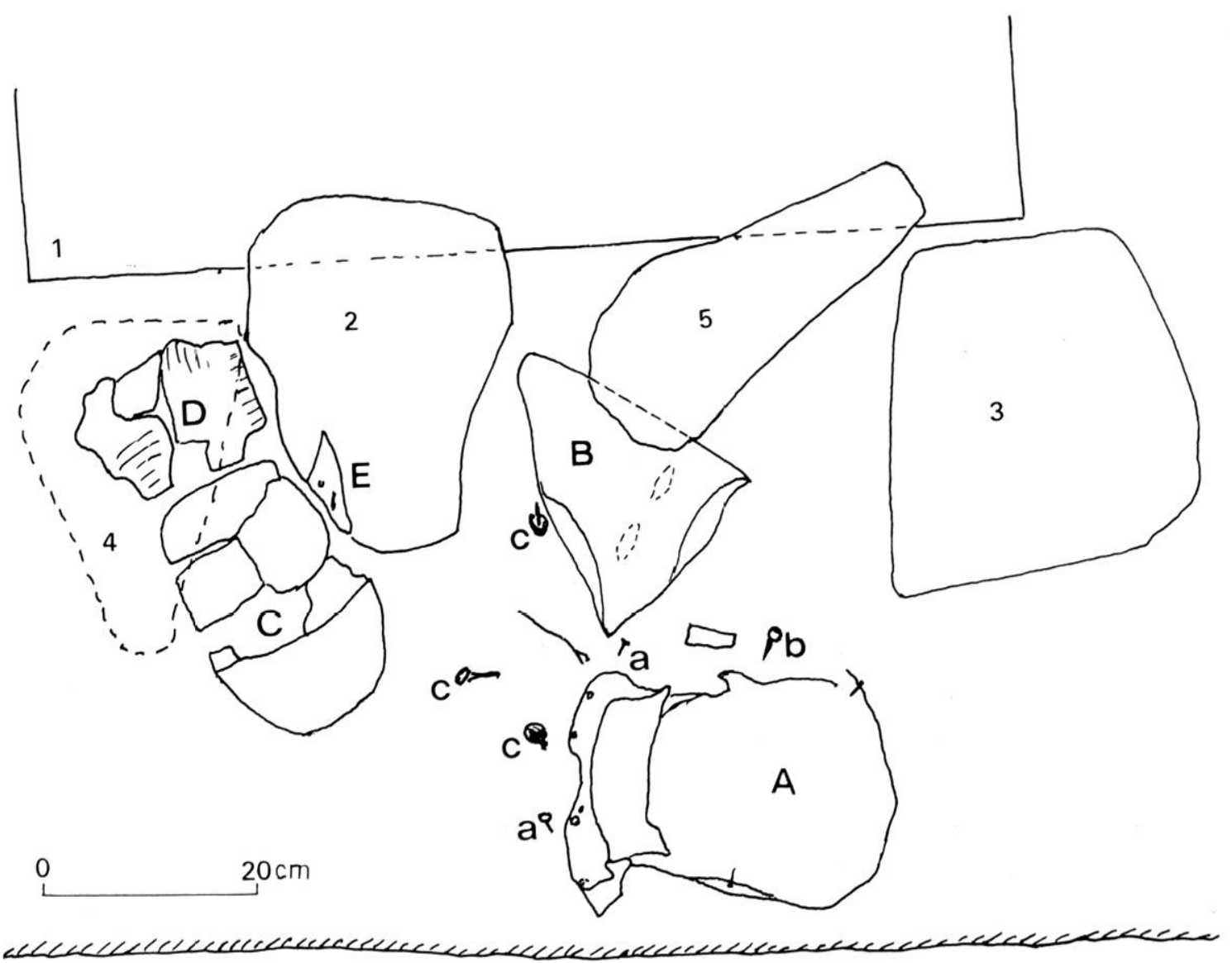

1 Conditions de la decouverte. $1:$ bloc de fondations en place. $2,3:$ fragments de corniche. $4,5:$ autres fragments d'architeclure. $\Lambda, B, C, B, E$ : divers élements en tôle de bronze. a : petits clous de bronze. b: clou en fer à tête sphérique en bronze. $c$ : gros clous en fer.

- sur lequel ne subsistent en place que deux blocs de fondations permettant d’évaluer les dimensions intérieures en élévation à environ $5,50 \times 3,50 \mathrm{~m}$. Mais si les vestiges en place sont très réduits et les dimensions médiocres, les éléments sculptés (blocs et fragments) recueillis aux abords immédiats de ce bâtiment attestent que celui-ci présentait une architecture soignée et classique (architrave, frise, corniche) à l'extéricur, ct une riche décoration figurée en haut-relief à l'intérieur, qui en faisaient un édifice de caractère aussi noble que le temple voisin.

En ce qui concerne sa destination, son plan (simple rectangle), sa richesse ornementale, les découvertes faites dans son périmètre ou ses abords immédiats (8 statuettes ou stèles votives de pierre, complètes ou fragmentaires) laissent penser qu'il s'agissait d'un petit temple, peut-être en rapport avec la source voisine. Le style du décor architectural et de la sculpture figurée, très proche de celui des éléments similaires du Temple, permet de conclure à une date de construction très voisine de celle de l'édifice religieux principal.

Quant à sa destruction, certains indices laissent penser qu'elle n'est pas intervenue beaucoup avant le milieu du $\mathrm{r}^{\mathrm{e}}$ siècle : en effet, sur la soixantaine de monnaies recueillies dans la fouille de ce bâtiment, 9 seulement ont été recueillies à l'extérieur ; 9 autres trouvées 

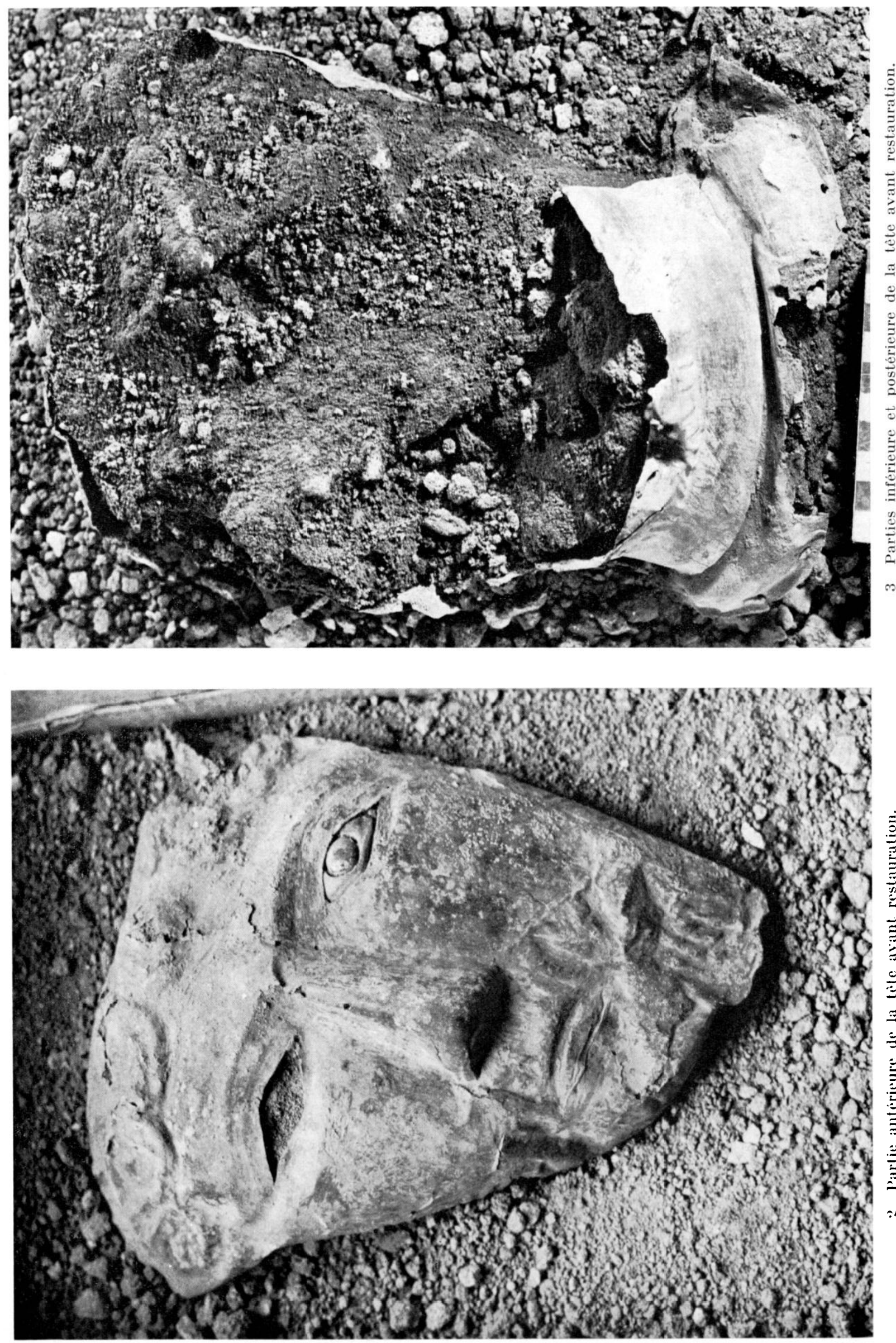

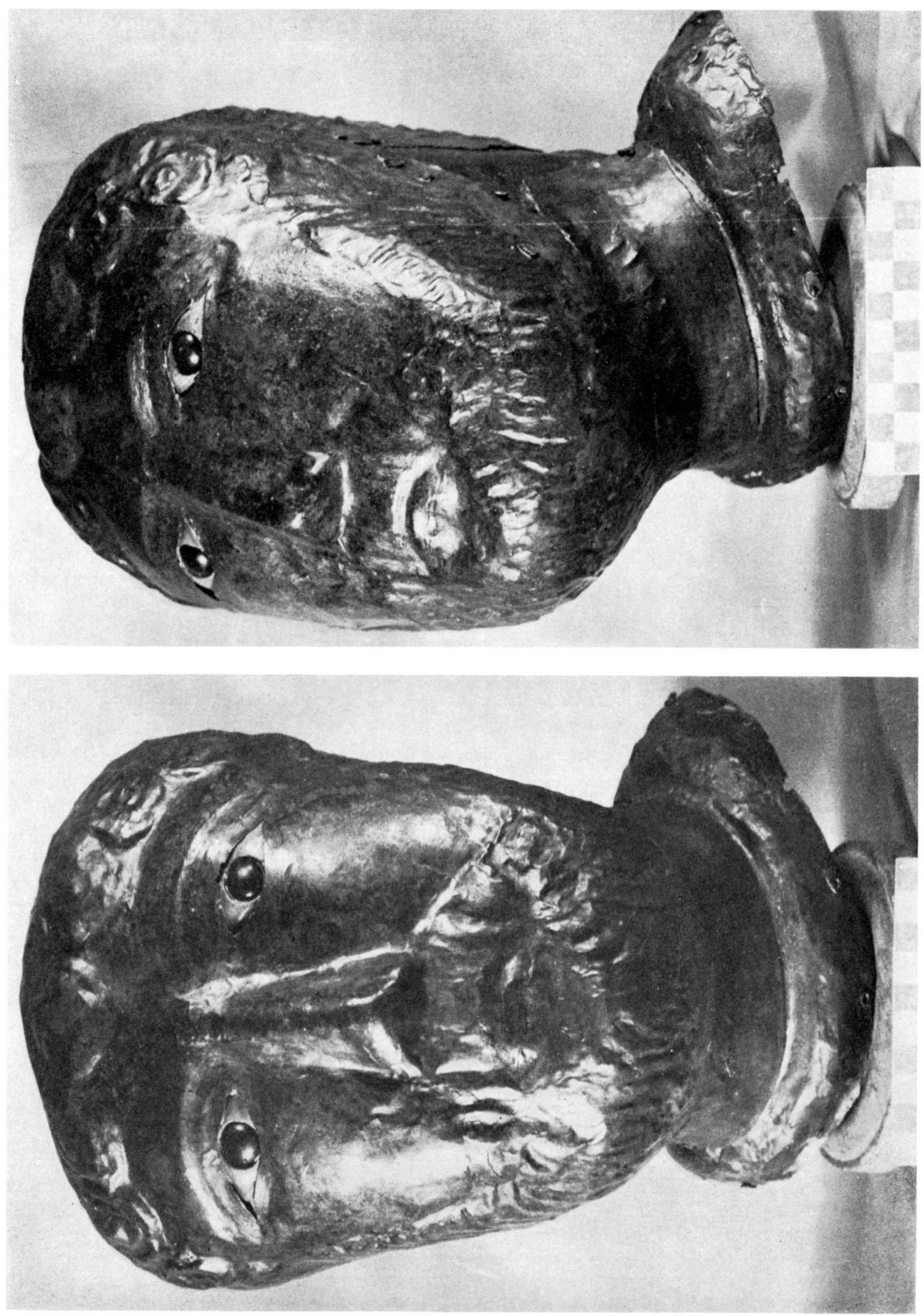


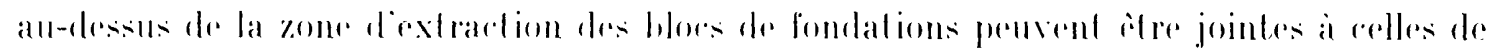

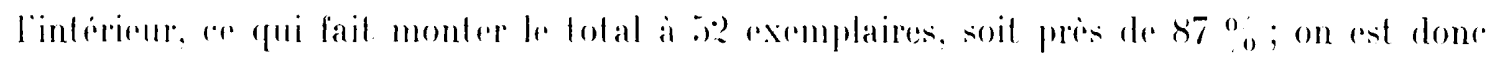
porti a penser que lensemble de res monnaies a lien dé abandonné dans le monument lui-meme ancore deboul, puisque les bouleversements intervenus lors de la destruction ont laisse subsister cette concentration ; cola vaut en particulier pour les monnaies les phus lardives: 7 monnaies d'époque constantinienne : la plus réente un follis de Treves,

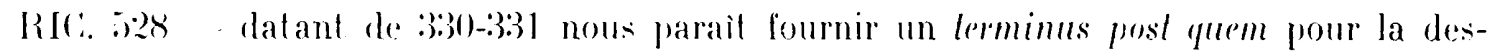
truction, due assentienlement, romme pour les autres monuments du site, a l'exploitation de ceux-ci en carriere. Ines degradations, pour des motifs mal déterminés mais vraisemblablement liés à des artivités rituelles, étaient toutefois intervenues dès le al e siècle (troisième quart de celui-ci), ainsi que parail l"indiquer une série de monnaies découvertes dans une sorte de fosse olservé dans la partie sud-ouest. L interprétation est ginér par la disparition totale du sol intérieur. probablement dalle, qui ne pouvail se situer a un niveau inférieur a celui des bloes de fondations encore en plare.

("est dans ce contexte de destruction, dans le périmètre de re bat iment. qu a été découverte la têle en toile de bronze, immédiatement au sul des bloce de fondations précités (en N. 24-L. 21), a t.) ('m au-dessus du radier de fondations du mur est. parmi des fragments sculptés provenant de la démolition du batiment.

Au moment de la découverte, la face, détachee du reste de la piere, se trourait juste a coté ainsi que des fragments de tòle de bronze plus ou moins importants; les notes et les photos prises au fur et a mesure de la progression du dégagement permettent de donner de la déconverte un relevé précis (fig. 1). C"est la partie face qui était la moins bien conservée, les bords étant repliés vers lintérieur ot en outre désagrégés par endroits (fig. 2). La pièce a fait lobjet diune restauration an Laboraloire didrelóelogie des Métaux a JarvilleNancy, sous la direction dr. II. A. France-Lanord, par les soins de M. Aimé Thourenint. Au cours du retrait de la ferre de remplissage que nous avions (fig. 3) laissée a l'intérieur de chacun des deux élements de la tite a l'arriver au laboratoire, furent retrousés, dans la partie fare, l'aeil droit, qui manquait jusque-li, ot une plaquette de bronze qui avait

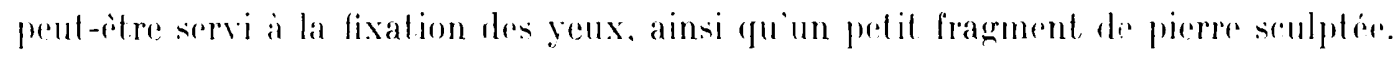

djoutons que deux maspues humains en töle de bronze, moins importants et moins bien conservés, avaient déja dé découverts antórieurement dans la fouille du temple de Genainville, en des points d'ailleurs non ibloignés du Bailiment secondaire VIII efe. infra, annexe IIT, pour l'un

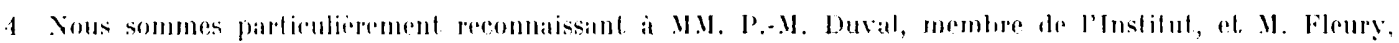

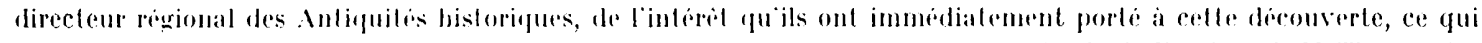
a permis le tratement rapide de la piece a Nancy. Celui-ei a comporle notamment, selon fes indieations de M. Thouvenin, le redressage des dements deformes frendu malaisé par l'écronissage du métal dì au fravail anlique de mise en forme

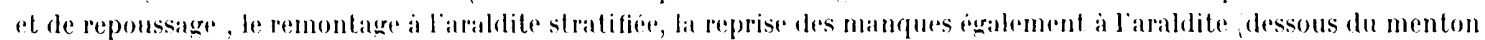
et bordure de la calotte arriere. la mise en teinte des parties pestaures el une imprignation de cire. Ice reassemblase

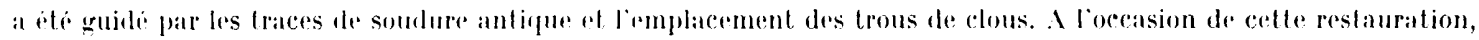
II. France-tanord el son adjoint II. Thouvernin ont fait de tris interessantes observations, fant sur la nature du

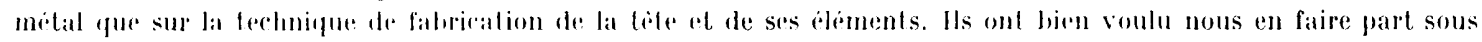
forme de notices detaillers, auxquelles nous nous refererons dans la presente etude et que nous donnons en amnexe pour deux d'entre elles. Qu’ils venillent birn lrouver ici, m meme temps que lexpression de notrestime pour l'habileté du travail accompli, celle de nos vifs remerciements. 

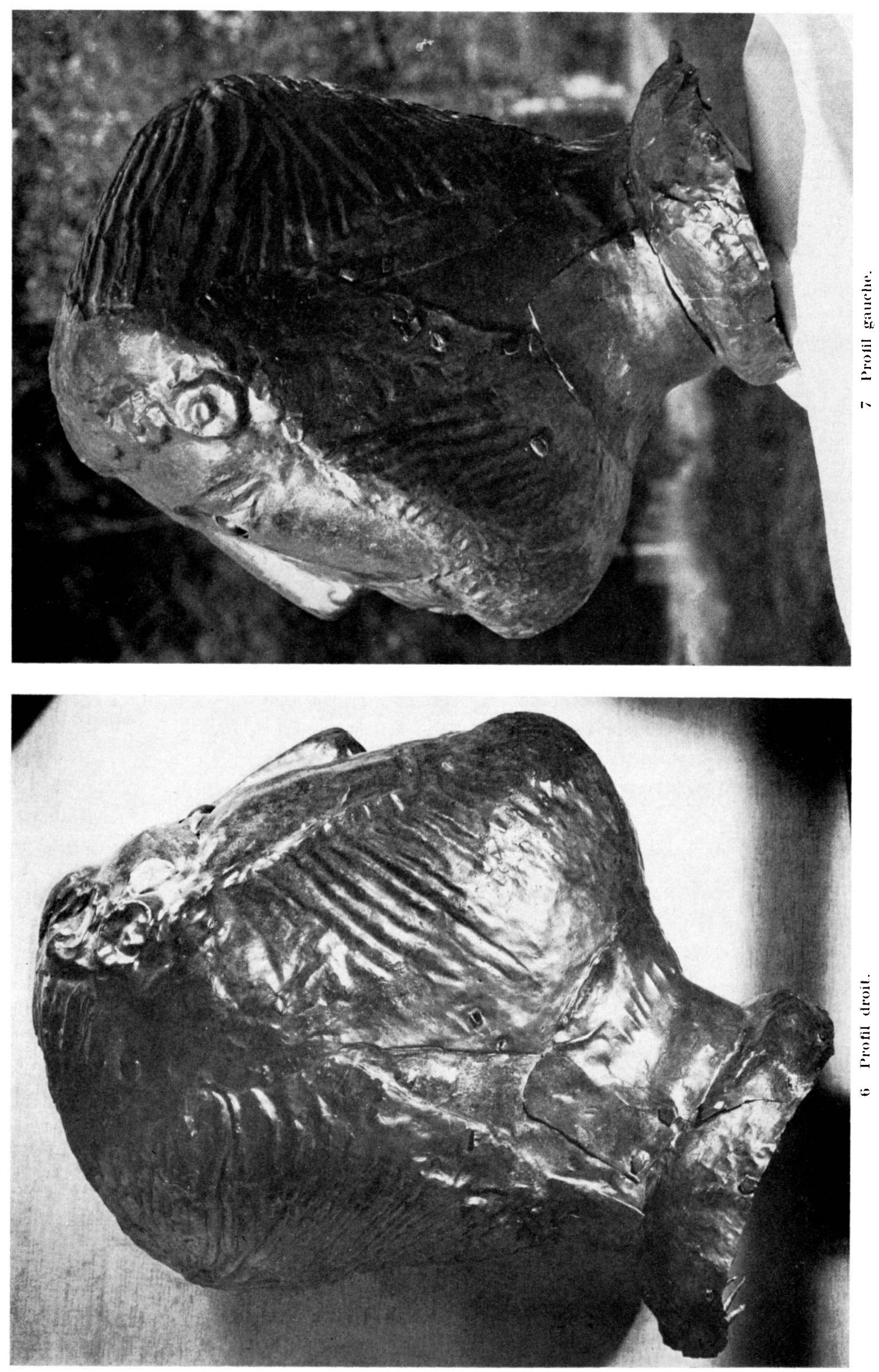

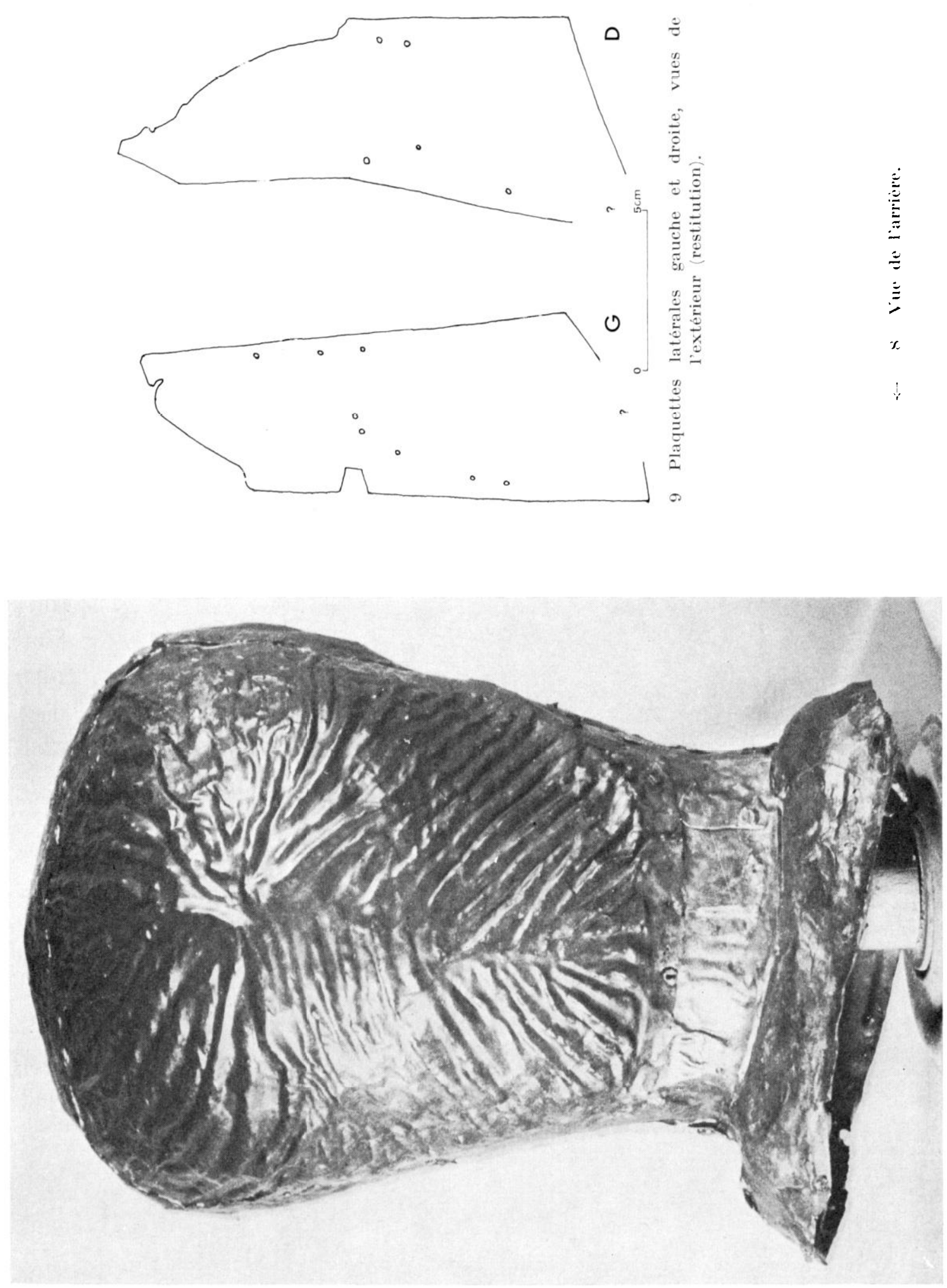
de ces masques; l'autre, plus petil et probablement de fonction differentre, fera lobjet dime ceturde distincte ultérieure).

\section{Lı lête.}

Il sagit de la figuration d'une lite masculine granderur nature, en metal hattu el repoussé, alliage de cuive, d'et ain el de zine. plus proche du laiton que du bronze efe infre, annexe I), aux yeux rapportés en os et pàte de verre 5 .

Caractéristiques matérielles : poids acturel : 195 go ; haul. totale : environ $10.30 \mathrm{~m}$ (variable selon linclinaison dont 0,24 pour la tete proprement dite ; larg. aux lomporaux): 0,175 $\mathrm{m}$; diam. du eou : 0.10 $\mathrm{m}$ en moyeme (0,05) d'avant en arriere; 0,105 d'un cote à l'autre); épais. actuelle du métal : 1 à $3 / 10$ de mm (selon X. Thourenin).

La tète proprement dite est formée de deux éléments principaux : une partie antérieure: le masque, et une partie postérieure : la pièer occipilale; de deux élements serenlaires - l'un à l'avant, l'autre à l'arriere pour le cou ; et de deux plaquettés complémentaires allongées grossièrement triangulaires angagées sous les autres pour combler les espaces subsistant entre celles, sur les roties figr. 9j. Lingagées regalement sous les élements

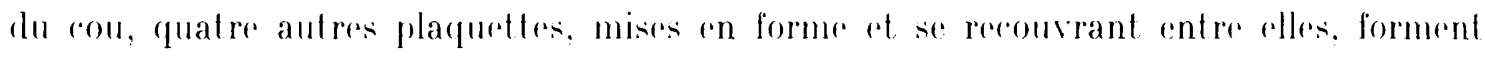
l'amore d'un buste (fig. 1 a 8 ). La piece oceipitale se raceorde au masque en s'engageant

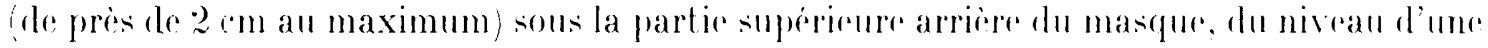
oreille au niveau de l'autre.

Toutes ces pieces ont à lorigine éte assemblées par sourlure à l'étain fobservation de II. Thouvenin. qui précise que re travail avait ete "exécute de manière satisfaisante, malgré une vraisemblable fragilités)). On remarque d'autre part à l'emplacement de's raceords, mais disposés de façon irrégulière ot non systématique le raceord ron-masque en est exempt), de nombreux petits clous conique tubulaires, renforcant l'assemblage. Nous en avons compte 25 y rompris quelques-uns tombes mais dont les emplacements sont bien visibles), aux(puels il faut ajouter 15) autres en place a la base de l'amoree de buste (fig. 10). Cés rlous ont dess longueurs allant de 1 a :? $\mathrm{cm}$.

En dehors de ces pieces, qui forment un ensemble complet jusqu'au niveau de l'amoree dr buste, on a recureilli juste a coté. a l'ouest : une piere mise en forme paraissant correspondre a une épaule avee départ de bras (ligr. 11 et I) du relevé fig. 1), ainsi qu'un fragment plus petit (long. : $8 \mathrm{~cm}$ ), travaille de facon semblable ot portant au bord un petit clou et l'emplacement d'un autere (lig. 12 et E llu relevé lig. 1); une plaque plate, allongéer,

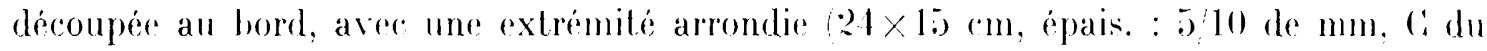

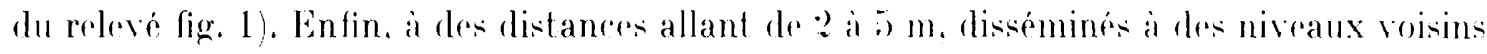

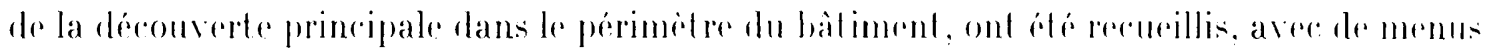

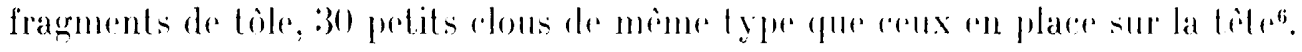

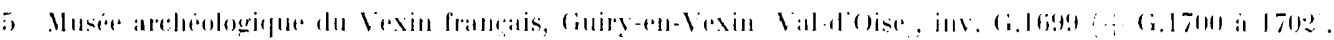

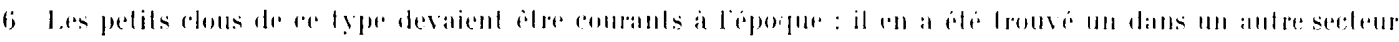

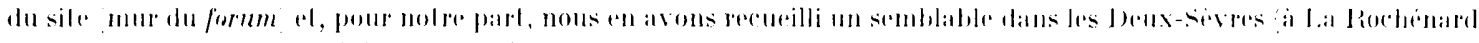

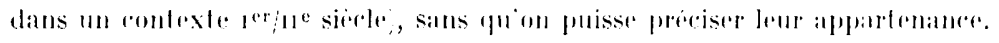




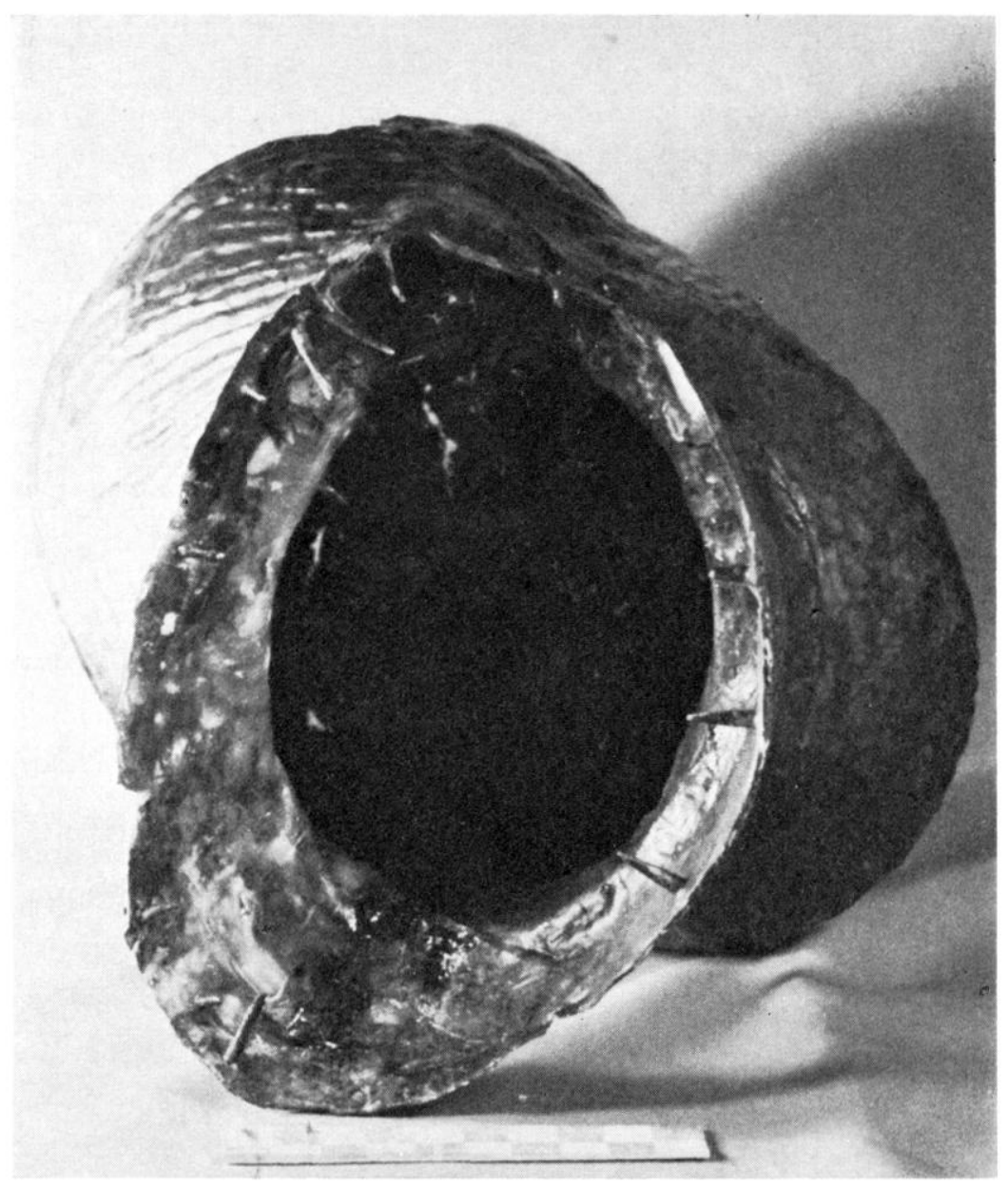

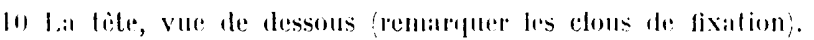

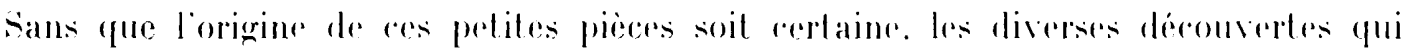
viement d'atre énumérés paraisient bien indiquer que la teite reenstituée appartenait it une piece plus importante, vraisemblablement is un buste veritable. Ce que nous interprétons comme dejpart de bras, sur le plus grand fragment recueilli a cote de la tète, présente des cotes paralleles qui feraient penser i une epauliere de cuirasse, mais on observe des cotes semblables en d'autres points du fragment (ainsi que sur le fragment plus petit) qui sont plus difliciles à interpreter coir fig. 11). Il faudrait en definitive avoir des éléments plus précis pour se prononeer sur la nature du velement que portait le personnage liguré.

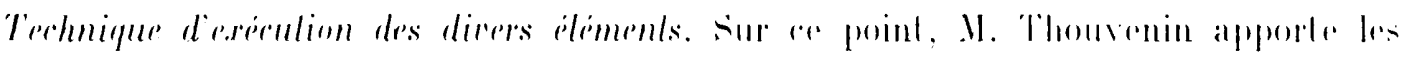
precisions ci-apres:

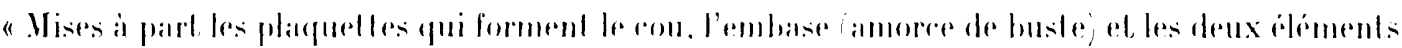

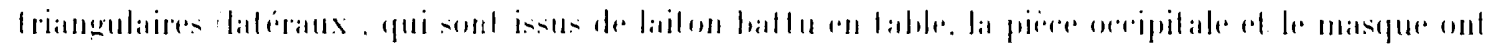

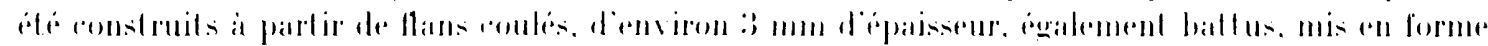

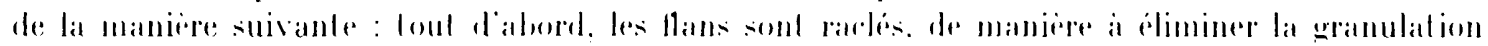

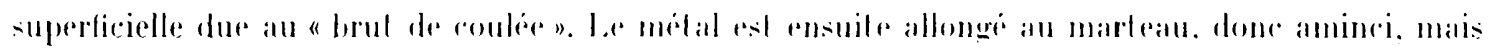


en réservant une épaisseur plus forte vers le rentre du llan. Cetle dispesilion permel l'emboulisiage au marteau de la tobe obtenue. tout en conservant an reux embouli une épaisseur sulfisanle. re qui rompense l'allongement, cela est particulierement néresiabe pour la mise en forme du nez. Jorsfure

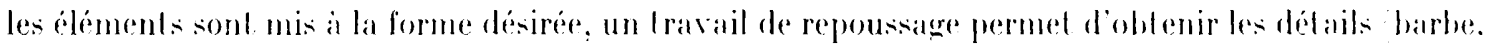

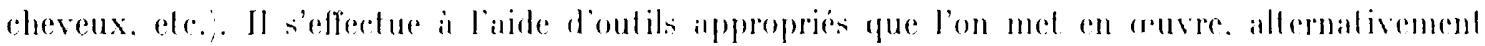
par lonterieur ou l'extéreur. en l ravailant sur un maleriau mou iexemple : poix-résine. hois lendre. sable plomb. Lemboutisiage seffectue sur un las cupulaire. mas une fermelure plus importanle

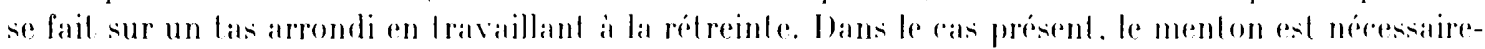
ment lraile par la retreinle."

ljoutons qu’il a dì en itre de mème pour la parlie arribe du cou. oi le travail du meilal se

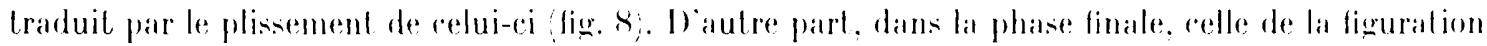
des délails. le Iravail de repoussage parait s'al re effectue essentiellement de l'intérieur. mais le sillon de la bourhe est evidemment fail de l'extérieur.

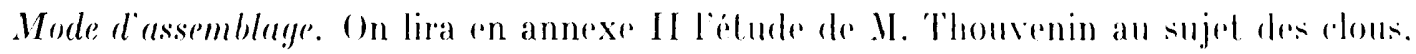
de leur morle debtention el de leur roble. Ca dernier point prete a discussion. Cas relous supposent la presener, sous le métal. l'un materiau dans lequel ils aient pu sonfoncer : du bois de sapin far exemple. selon la sugerestion de M. Thourenin. Mais faut-il suivere

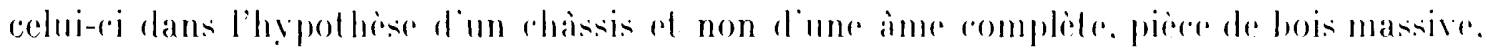
ayant grosiderement la forme de la tate ou do buste, el sur laquelle les divers ilements de tole de bronze auraient eté fixés? Il paraìt diflicile de se prononeer. on notera simplement

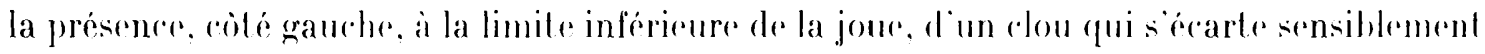

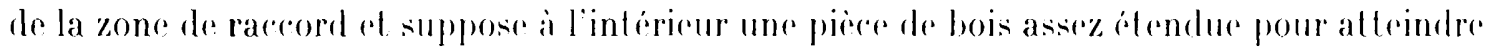
cette région ifig. 7 ).

Comment dautre part interpréter la presence de ces roms. alors gue lon observe

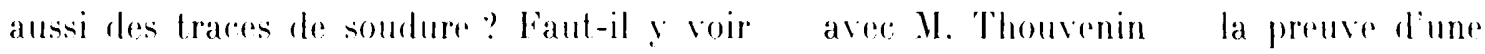
réparation posterieure a lopération initiale de labrication? Xe prent-on penser phutot a un changement de dispositions et a un repentir de la part de l'artisan lui-mème. ronstatant

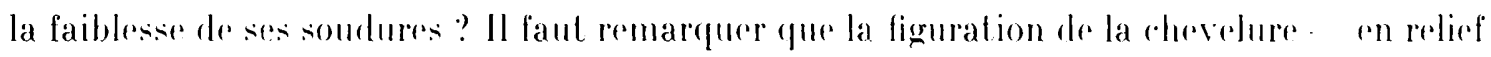

sur la piece oceipitale sarretre rers lavant. en particulier dans la partio inferieure fig. 7 ) a $1,5: 2$ cm du hord. eomme pour former une fenillure d'altente pour l'emboitrment du

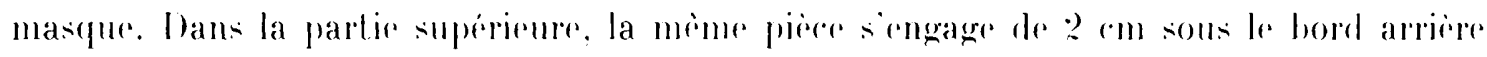
du masfure re qui parail exressif sur le plan lerhnique. On peul done se demanter si la disposilion dassemhlage qui nous est parrenue ol telle quille a ete consolidé par la restanration etait bien erelle qui a ait ele inilialement prevue par l'artisan : on pourrait par la pensere ens appuyant sur un montage photographique faire pisoter le masque par rapport a un axe central transirepal. de facon que lo masfue soit moins incline vers

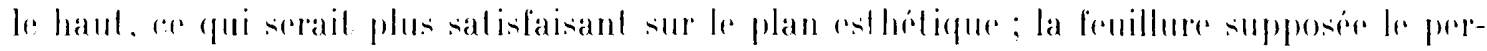

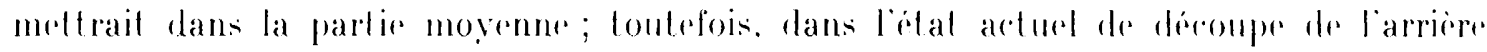
du masque. un manque apparaitrait au niveau du front. Ia disposition artuelle d'asiom-

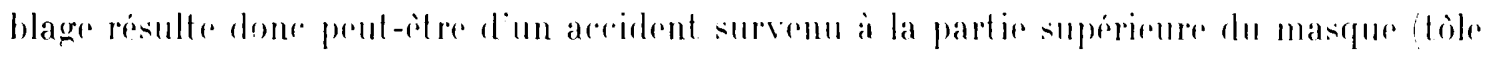

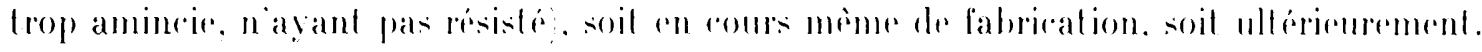

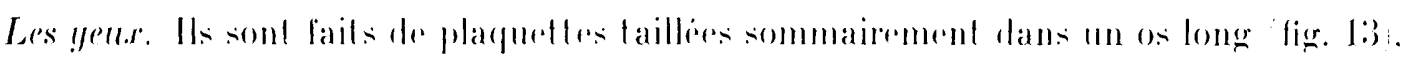
mais scupptes sur la lare visible de lacon a presenter un leger relief ron ovale a pointes. 


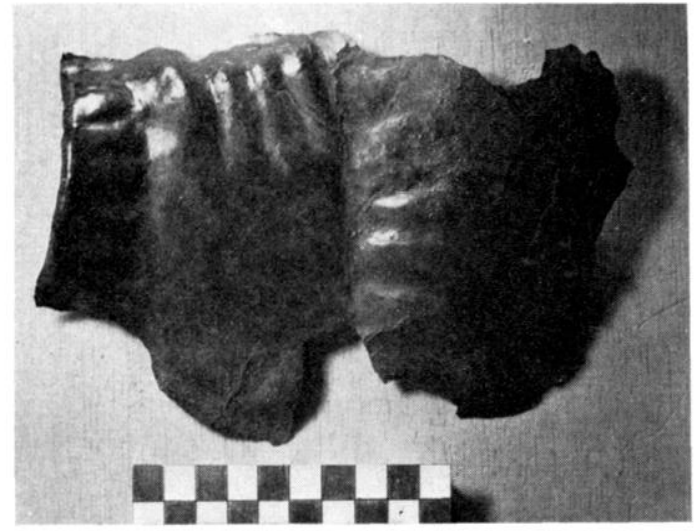

11 Pièce D : partie de buste (?).

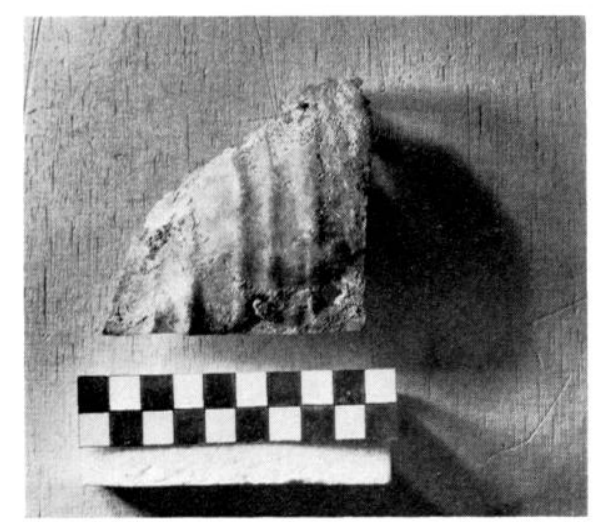

12 Pièce E.

14 Profil gatuche; vue de detail montrant l'oreille. $>$

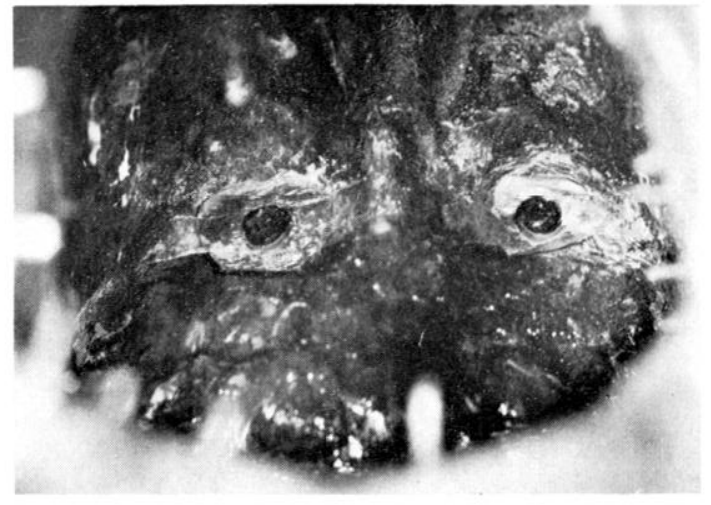

13 Les yeux, vus de l'intérieur (après restauration).

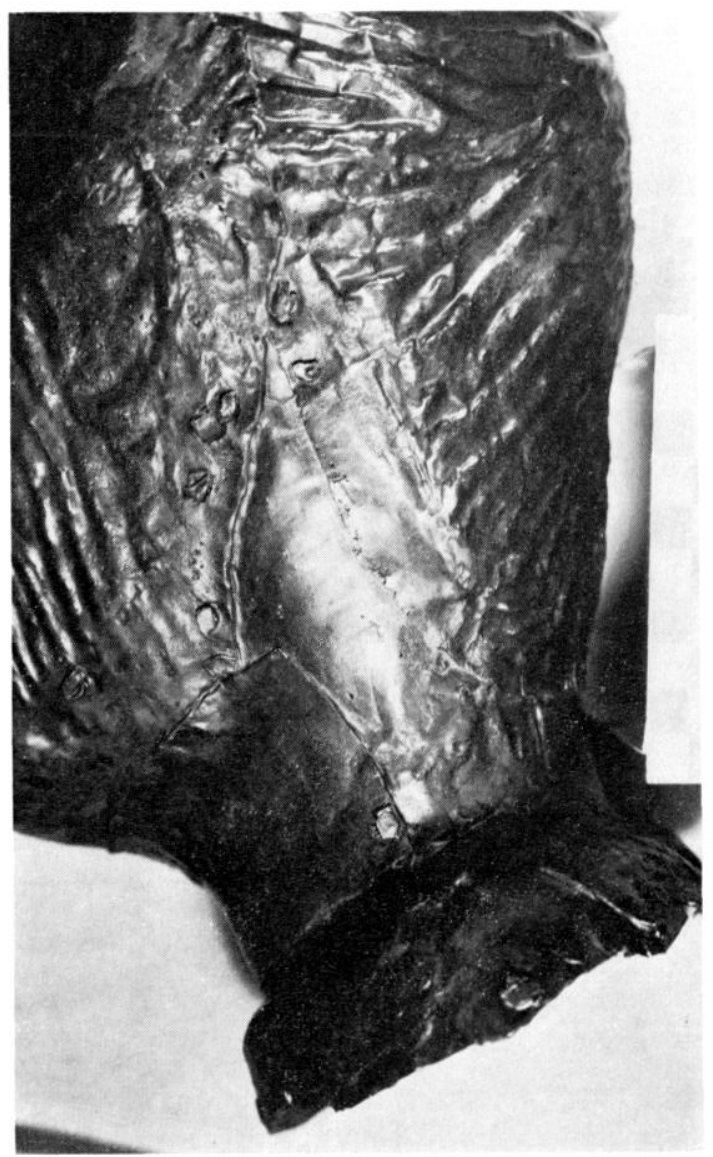

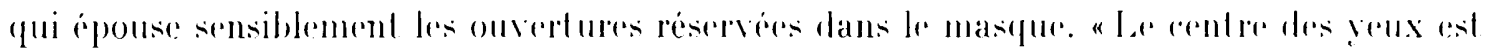
perce a l'archet (traces de fleuret) d'une ouverture circulaire. dans laquelle est encastre un rabochon de verre blen foncé ... obtenu a l'aide d'un fragment de verere refondu (mise en forme hemispherifue obtenue automaliquement au rérhauffage " 1. Thomsenin).

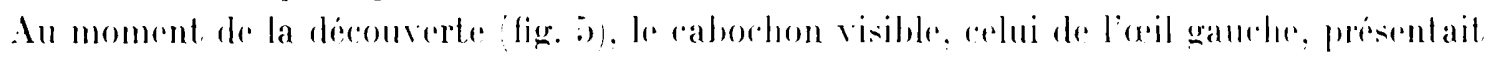
en surfare une pellicule blanchatere, sauf au centere, ce qui donnail limperesion diun iris aver sa pupille; mais il devait sagrir d'un phénomene fortuit. naturel "dépoil raleaire 


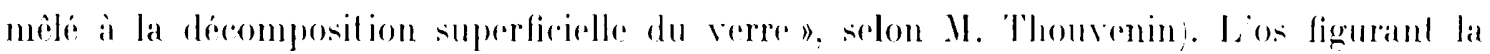
sclérotigue a, d'autre part, verdi sous l'effed de loxpration du métal.

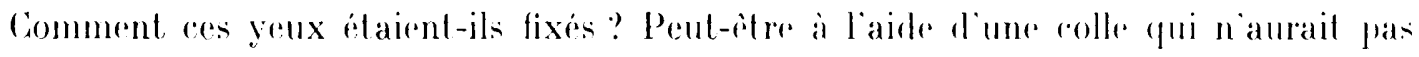
laisse de traces, colle qui aurait pu également fixer les cahochons de verere dans leurs cavités. Peut-itre la petite plaquette (5,5)2.8 ('m) recurillie a l’intérieur du masque pres des veux avaitelle contribue a cette fixation : placée entre les yeux, chle aurait pu lout juste recourrir les extremites les plus proches des plaquettes dos ; de meme qu une autere un pell plus grande $(7 \times 4 \mathrm{~cm})$, trouvée a :3 m de là, clle aurail pu maintenir la matiere collante

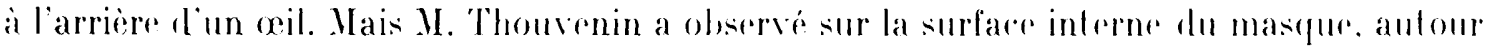

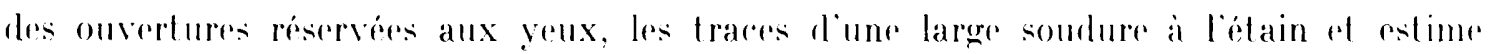
"logique de penser que les yeux arluels ont remplace dautres yeux, qui se trouvaient fixés en place par l’intermédiaire d’éléments métalliques soudés a l’ótain ». Il ajoule que "la forme des yeux en os, a leur revers, ne permet la pose d'aucune couronne métalligue de sertissage, ni de souduren; ; exte disposition lui paraìl con firmer un travail de secende main. Que le mode de lixation des yeux ait éte modifié a un rertain moment. possible. Mais lielée que les yeux qui nous sont parvenus ne soient fas resux du travail inilial ne nous parait pas. malgre lobservation prééclente, s̈imposere.

La plaslique. Le personnage possede une barbe, ligure par des reliefis, grosisiemement paralleles, qui rejoint une moustache figurée de mème. Sous le menton, le cou presente une série de petits reliefs, rectilignes (batonnets de $10 \mathrm{~mm}$ de longuedur). plus ou moins paralledes, figurant semble-t-il mais de facon pent realiste, un prolongement de la harbe ce mode de traitement differe sensiblement de celui de la harbe proprement dite et Ar la chevelure ot fait penser a l'intervention d'une aute main. La chevelure comporte une serie de bourles (spirales en forme de boutons), au nombere de ?, encadrant un front bas. ch, a l'arriere. des merhes rayonnant a partir de la pointe de loceiput pour la part ie supériecure et divergeant a part ir d'une ligne sensiblement médiane au-dessous ( fig. 8). Cees merches. exécutées de la mème manière que la barbe, se prolongent à la part ie supérieure de la pièe. antericure (masque), en direction des boucles, sans les rejoindre.

La face est plate, le nez assez proéminent. mais trop rectiligne et sans modelé, la bourdere petile (1 cm) et faiblement marqué par un sillon incurvé aux extrémités tombantes. Au premier examen. on ne remarque pas les oreilles lant le relief qui les indique est pen arcentue. Cille de gauche apparait bien cependant sur la photo de detail (figr. 11), marqué vers larriere par un bourrelet ovale prenant la place des reliefs figurant la barter ; celle de droite est moins visible, mais il faut remarquer que ce cote du masque at ait plus abimé.

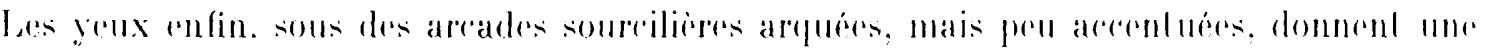

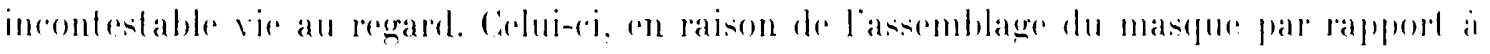
la pienere oceipitale, apparait dirige vers le haut.

Au terme de cette description, on soulignera que cette tite om re buste aux traits

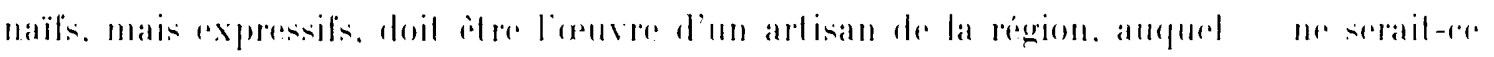

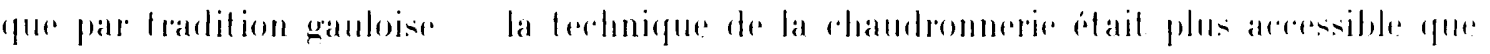

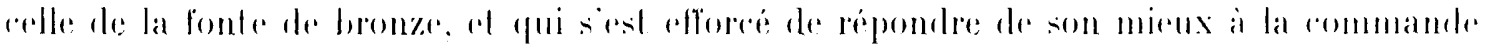

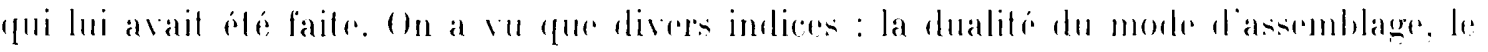


problime de la fixation des geux, le trailement particulior de la figuration de la harbe: sur le cou, peuvent faire penser a deux phases sureessives de réalisation. On manque cependant d'élément déterminant pour en dire davantage sur ce proint.

\section{Elude comparative.}

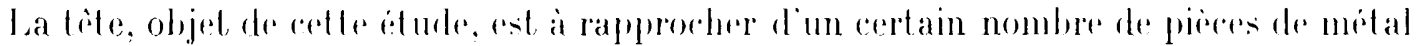
hallu et repoussé figurant des teites ou visages humains aver une selhematisation des traits, mais sourent aussi une stylisation lypiquement cellique, qui en font les témoins manifustes: d'un courant particulier de production généralement trés éloigné de l'art classique. I,un des premiers a avoir attire lattention sur centensemble de documents est R. Lantier a

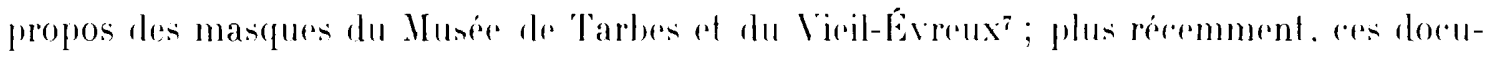
ments so trourent a noureau réunis dans des bludes plus larges de spécialistes tels que

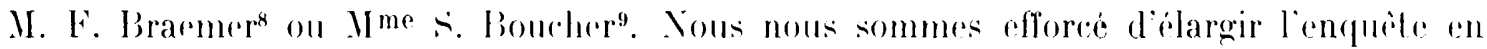
recherchant les pieres moins ronnues ou les découvertes nouvelles. Yous réunissons res pièces de comparaison dans une série de breves notices (Annexe IV) anxquelles liétude ci-apres renverra (renvois enter erochets). Sous placant pour cette etude comparative sur un plan principalement technique, nous navons fait figurer dans cette série de noties que des pièces executers au moins partiellement en métal haltu et repoussé bronze principalement. En fait, en ee qui concerne ce métal, on comait un certain nombre de masques, tites ou bustes en fonte creuse appartenant. de plus ou moins pries, par leur esprit et leur esthétique, au même courant culture ${ }^{10}$.

Les pièces de comparaison. apparentés par la teremique at les raracteristiques générales, diffèrent parfois sensiblement dans les détails. Ies plus nombreuses correspondent a des figurations sensiblement grandeur nature; plusieurs cependant sont plus petites : celles du Mont-Berny [5, Montsérié [6, Augst 99?. Marnherm [10?. La Croix-

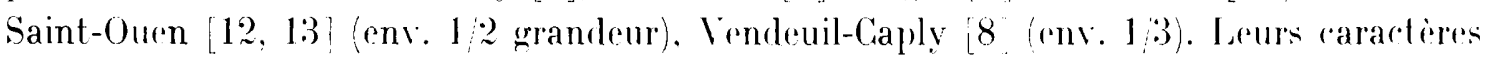
sont tantiot masculins, tantist féminins, parfois douteux.

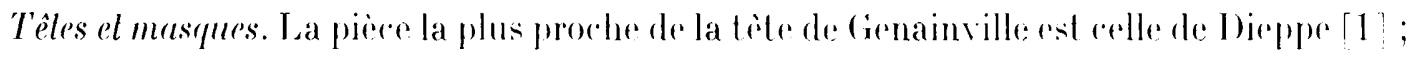
clle l'est par les dimensions (grandeur nature. comme la notre) ef par le fait quili s'agit

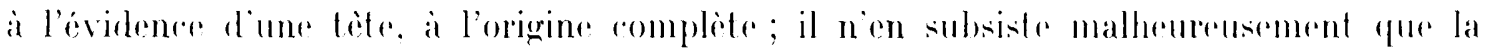

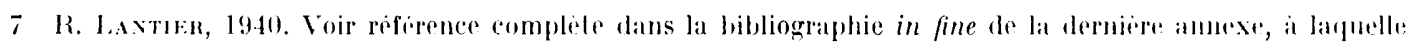
nous renvoyons systematiquement pour les ouv rages ou articles les plus fréfuemment cites.

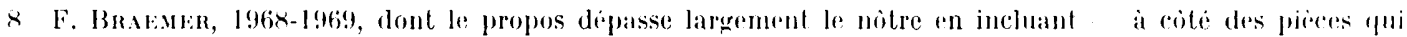

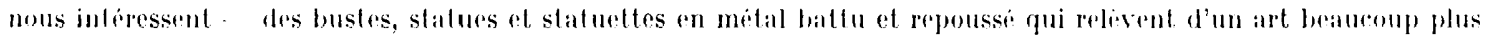
"lassigue, bien cque comportant des traits de provincialisme que l'autrur s'atlar'he a souligner.

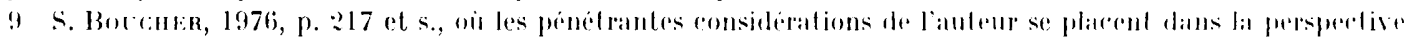
d'risimble des bronzes figurés de lin cianle.

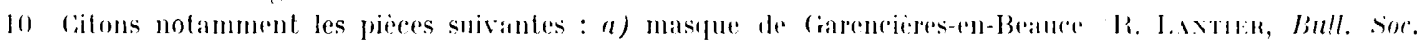

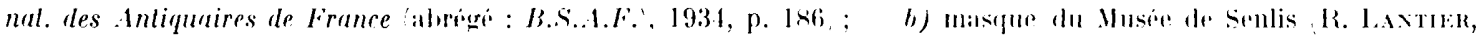

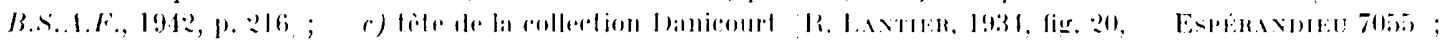

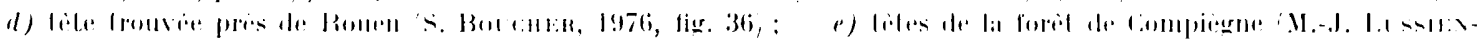

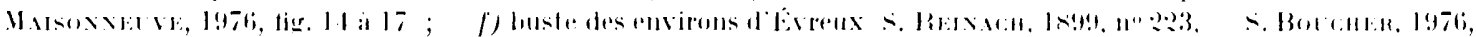

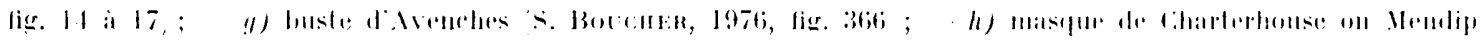

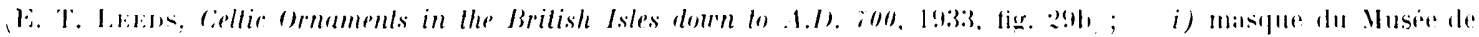

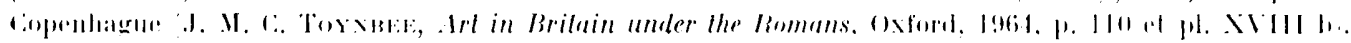


pièce oceipitale, présent ant chevelure et cou, qui appelle naturellement une piece antérieure

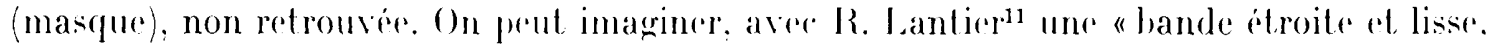
réservée aux extrémités du masque" pour permettre un emboilement, tout en faisant observer que pour lesthétique. Ir reeourrement de la piece ocepit ale par la piece antérieure aurait été plus logrique ; mais la piere conservée ne présente effectivement pas de bande lisse au bord, non plus d'ailleurs que de traces de soudure a l'intérieur. L'assemblage par emboîtement et sourlure ne est donc pas absolument certain.

l a solution envisagée par R. I antier se fonde sur la présenere d'une hande lisse olservée sur d'aulres pieces comparables: an particulier ceolles du Mont-Berny 5] el de La CroixSaint-()uen 33 . Ln a qui concenne la premiere (roir Annexe 11 , lig. 20) la bande lisse a $7 \mathrm{~mm}$ de largeur; elle a ju permettre un tel assemblage; la pièce presente actuellement un certain écrasement latéral, qui peut expliquer le redressement du bord supérieur (bien visible do profil) lequel ne permeltrait guere l'insertion sous une piece occipitale dans cet état.

Cela nous parait beaucoup moins vraisemblablik pour la seconde (Voir Annexe IV,

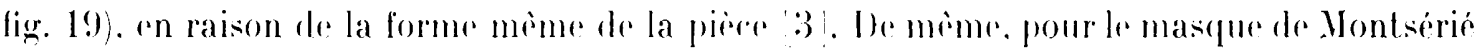

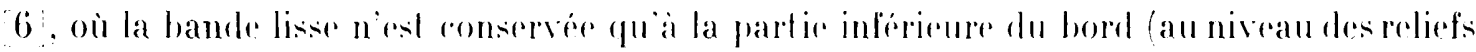
figurant la (hevelure).

On a prétendu parfois que les derux masques en argent de Cotre-J)ame-d Allencon 16, 17 présentaient exalement a l'arriere une "fenillure dattente depourve de repoussé ...

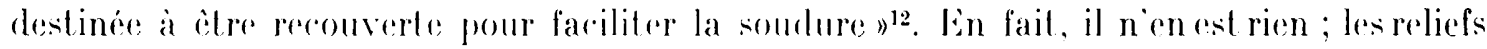
figurant la chevelure atteignent le bord de la piece. la plupart des autres pieces de compa-

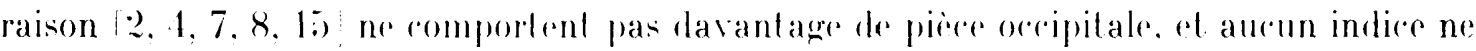
permet de penser quielles ren aient jamais posierlé.

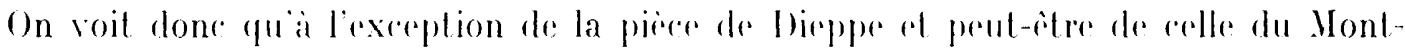
Berny, ces pièes different dre celle de Cirnainville : sur un point essentiel, rest que ce ne

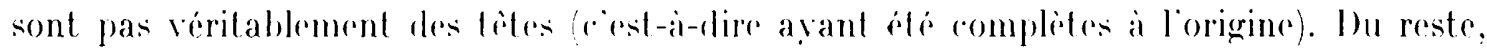
s'il en avait été autrement. il serait bien étonnant que l'on n'ait pas retrouvé quelques

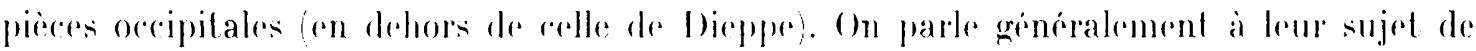
"masques"; cette expression rend compte, en effel. de lasperel materiel de ces piècers (simples visages) ; clle ast en lait ambigü : on lui romene un sens plus étendu en en faisant une categorie particuliere de bronzes figures se distinguant des portraits par l'absence de traits individuels of correspondant a une forme originale, "indépendante de lart et de l'esprit classique $)^{13}$. L'expression s'applique alors aussi bien a des masques au sens formel

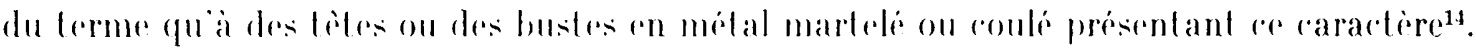

$1101 \%$. cil.. 1). 11:3

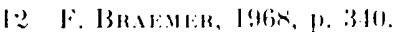

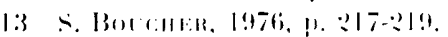

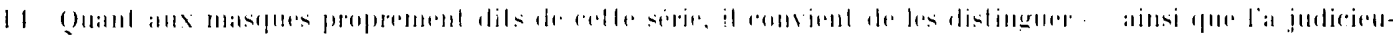

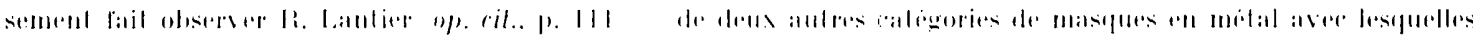

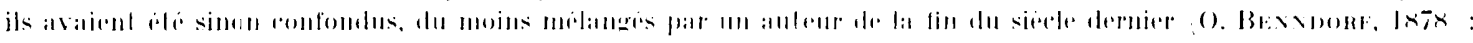

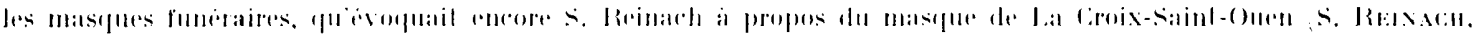

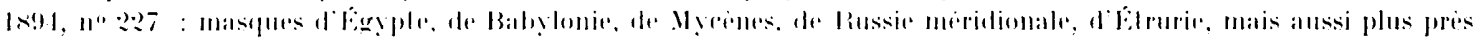




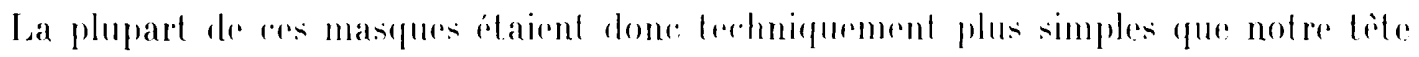
de Cienainville. Le masque de la foreit de Brotomne. qui sarrete au niveau du front. se complétait peut-itre par une pièe ligurant lo haut de la lete. El pour une piece beaucoup plus évoluce sur le plan st ylistique. le buste de Varnheiun 10, on restitue au-dessus du front coupe comme pour le masque qui préciele - une coiffure importante qui aceenture son caractere celtique. A la limite de la série que noms avons retenue dans celte étude. les deux lites de la lirois-saint-()uen, qui sont "n bronze coule pour l'esientiel, comportent une piece oceipitale en toke, dont le mode de fixation est particulierement sommaire voir

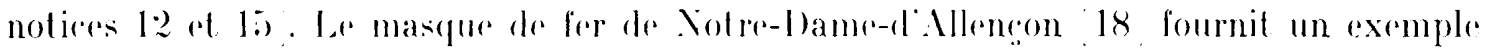
différent : les trois pieress qui le composent sont réminis interieurement par a languettes de mème métal, rlonées et non soulées.

Le mode d'assemblage des divers éléments composant le erpers du dien de Bouray 11

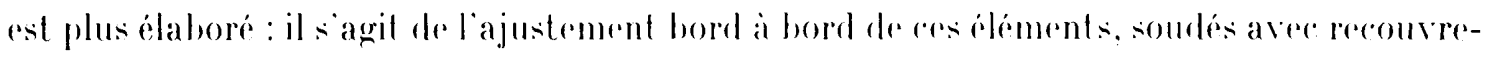
ment des joints par des haguettes plates ; lapplieation diune telle terdmique au raceordement des deux parties deun lite etait moins conerable pour des raisons esthétiques; le, problème ne sest pas pose pour le dieu de liouray les deux parties de la trite etant coulées, ce qui leur donne une épaisseur suffisantr pour permettere une soudure directe des bords.

R. Lantier ne se bornait pas a pensere que les masques dont il vient dritre question correspondaient a des tibes completes. il estimail que cedles-ci se fixaient sur un torse, le dispositif en deux parties ne pouvant "avoir d'autre utilite que le faciliter la mise en place de ces tites" sur celui-ci 11 . Remarguons cepentant que ce dispositif, dans la mesure ou il aurait existé, aurait eu au moins aussi l'interest de fariliter l'exécution dre chaque pièce au repoussé. C'est un souci de simplification qui nous parait en lélinitive expliquer l'existence de ces masques. Sil est vai que la teile revetait une importance particuliere "dans

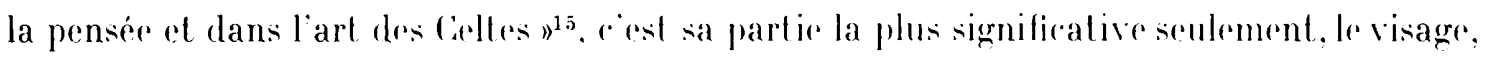
qui etait ainsi le plus somvent figuré.

On considere généralement que ces masques extaient fixes sur un support de bois.

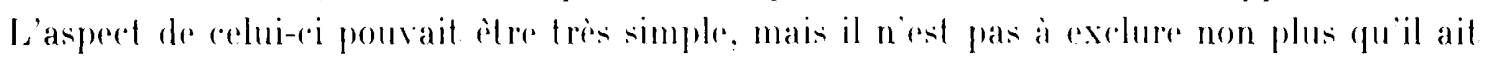
été parfois sculpté plus ou moins soigneusement pour former un buste ou une statue comparables aux seuptures de bois que des découvertes ont réveless aux sources de la seine ou à Chamalières. L ne trouvaille d'un autre genre faite dans la fouille de Cienainville montre

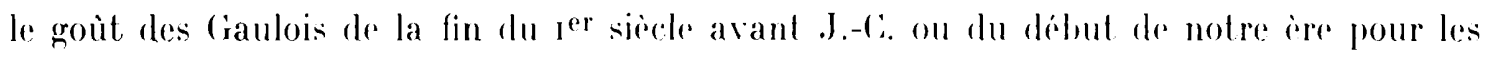
figurations composites : en l'ocecurrenere une statuette en pierre avere trite rapportée en une autre matière's.

Le mode de fixation sur le support de bois pouvail varier l'un ras à un autre. Le masque de Montserie 6 se prolonge par un eou en forme de "douille ouverte en arriere et

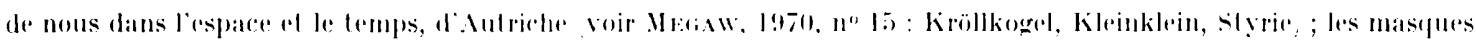

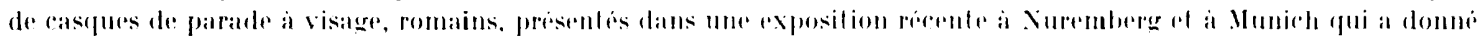

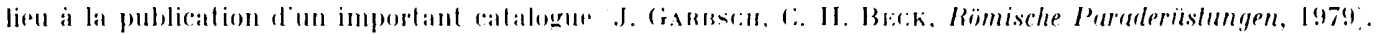

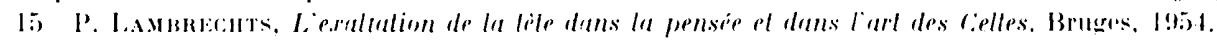

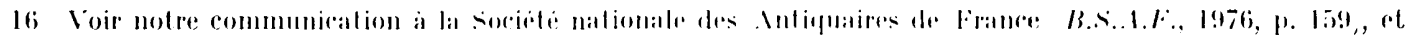
Bull. arch. du Verin francais, $11,1971$. 1. $: 9$, tig. 1.
} 


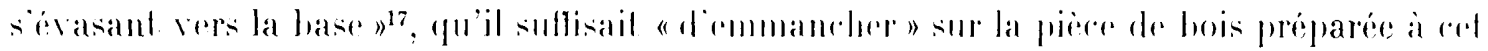

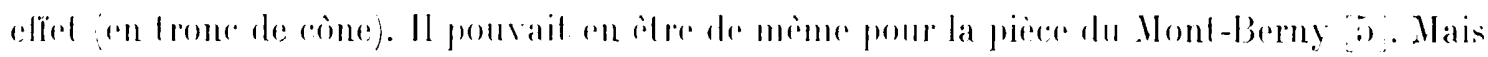
dans les cas les plus nombreux, des trous, quon obserer pres du bord de la piece en divers points: montrent une fixation par des clous : le masque de Yotre-Dame d'Allencon, le plus

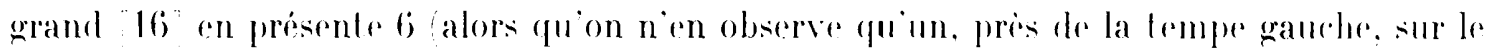

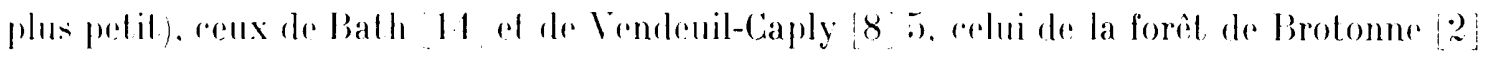
un seul pres de la tempe gauche, mais cette piece est trop incomplete pour quon puisse voir l'emplacement des autres. Pour le premier masque, ainsi que pour celui de Bath, les trous avaient été percés a partir de la face interne, ainsi qu'en témoignent de petites liveres de métal sur la face externe; ces avant-trous s'expliquent sans doute prar lutilisation de clous trop faibles pour percer lo métal, peut-itre de mime type que ceux de cienainville (roir Annexe II) dont la présence est assez discrete. Lin revanche, a Vendeuil-Caply ainsi que pour le masque de la forèt de Brotonne les trous ont éte percés de l'exlérieur. par conséquent vraisemblablement au moment mème de l'enfoncement des clous : l'un de ceux-ci subsiste dans la chevelure et présente une large tite an bossedte qui prend une valeur décorative s'aceordant mal avee une ceure dre statuaire meme fruste, de sorte quion peut se demander si ce petit masque avait bien la mème fonction que cens, dre plus grandes dimensions, dont il vient dètre question.

En ce qui concerne le mode de lixation, le masque du Vieil-Érenx pose un probleme: le visage est percé de huit trous, relativement grands 7 a 8 mm forés de l'intérieur, dont on sexplique mal la répartition anarehique. s'ils ont hien ele pratiques pour la fixation sirr un support de bois.

Liun des eléments qui frappent le plus dans les diverses pieres réunies dans celle éturle est certainement le mode de liguration des yeux. Sour résere du cas isolé du masque de

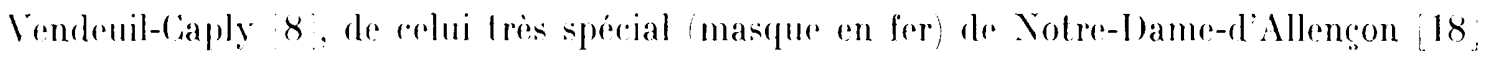
el de ceux particuliers igalement sur le plan stylistique el géographique d'Augst et Marmheim !), 10, on rencontre deux morles principaux. Le premier consiste en un ovale allongé, en pointes percé d'un trou rond a l'emplacement de liris (et de la pupille); le contour de lovale peut etre marque soit par un petit relief (repoussé de l'intericur), comme à La CroixSaint-()uen 3, au Mont-liserny [1, a Yotre-I)ame-d Allencon 17], soit par une petite grorge, comme en foret de Brotonne 2 , a Bath 14 et a Genainville pour le masque (Annexe III). Ce mode de figuration cost celui que présentent les masques ou bustes en relief ornant le hassin de Ciundestrup, ainsi que d'autres masques ornementaux typiques de la derniere période de l'art celtique so sur le chaudron de Gundestrup, les trous ronds portaient des pastilles de verre de couleur rouge ou bleue (an partie conservés ${ }^{19}$, qui laissent penser qu il pouvait en ètre de mème dans les autres cas mentionnés ci-rlessus. A liath, ces pastilles

17 R. J.1.TH:R, 1910, p. 105.

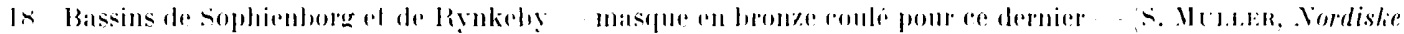

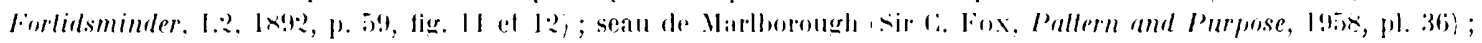
rhale? de stanwick sir l. Fox, op. cil., pl. 43 h.

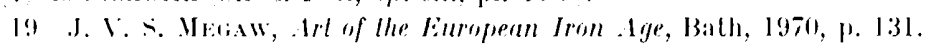




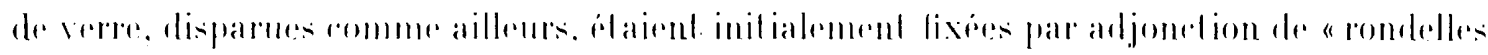

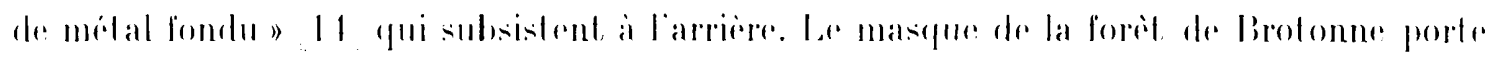
egalement des traces banchatres a larriere des yeux, restes de la lixation des pastilles de verre. Labence de traces diune matiere de fixation dans daul res ras 3 . a renel la grénéralisation de l'hypothese sujette at caution.

Dans le sereond mode de figuration des yeux, r'est lout l'omplarement de l'oril qui est svidé pour perevoir une matière dapport qui a malheureusement disparu dans les trois cas qui nous interessent le plus directement : les masques de Montsérié 66 , du Vieil-Évreux t] et le phes grand masque de Notre-Dame-d Allencen [16. Les yeux rapportés sulsistent 'n revanche sur le dieu de Bouray (pour l'un d'entre eux. le gauche) el sur la trite ayant dì appartenir a une statuette comparable de la collection l)anicourt, ainsi que sur deux pertites tites trouves a La Croix-saint-0uen (comme le masque no 7$)^{20}$. Sur les deux premieres pieress, les geux sont faits d'un grobe de verre bleu foncé an centre - pour löiris el la pupille et hanc autour, sur les deux autres d'une pastille de verre heu foncé fixée dans lorbite par $u$ amalgame hlanchitre. Le travail de mise en place est assez maladroit. Les veux de notre lite de Cienainville se rattachent lans une certaine mesure a ce second mode de tiguration, mais le procédé est iri plus élaboré of le résultat obtenu incontestablement meilleur. Il se rapproche davantage du procédé romain classique. tel que te montrent

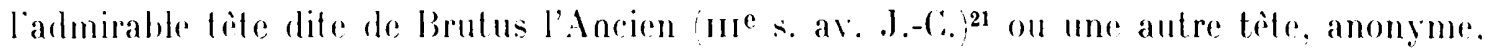

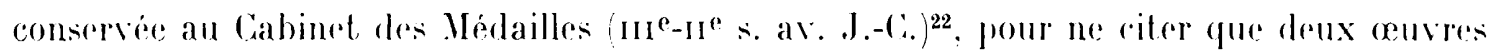
lien connues. Pour la premiere, les yeux sont donnés lantôt comme en ivoire $e^{21}$ lantòt comme en paite blanche, avec iris en verre brun-rougere. La comparaison se limite bien contendu a ce point particulier.

Pour le reste, notre tite de cienainville est, comme on l'a dijia rlit, a rapprocher, par la schématisation des l raits ou le st yle des pieces qui se trourent réunies dans les notires des Annexes III et IV. La schématisation of la stylisation varient cependant d'une piere a laule; elles sont certainement fonction dess conceptions de l'art iste plus ou moins proche's des lraditions de l'art celtique, mais aussi de sa plus ou moins grandre hahileté a mait riser la ferhnique du repousse. Sur te masque en chain de Bath, qui est le plus fruste de la série, lartisan n’a pu "sortir" le ne\% an repoussis et a dio le soulder en ajoutant, a l'arriere une bande de renfort.

A lexeeption des masques en argent de Notre-l)ame-d : Allencon qui paraissent bien avoir éte travaillés alternativement de lintérieur et de l'extérieur. le travail au repoussé scmble avoir été, comme a lienainville, essentiellement exécute de lintérieur. sauf pour

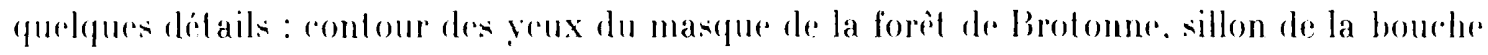

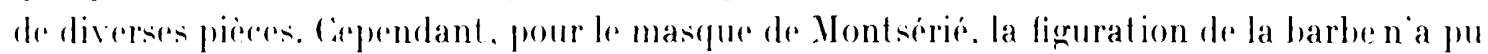

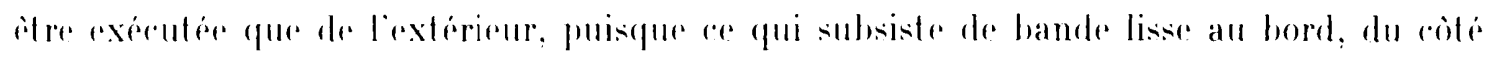

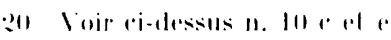

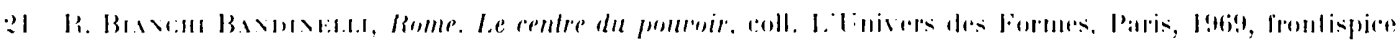
(4. ए. 3314 .

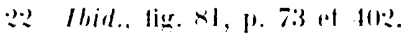

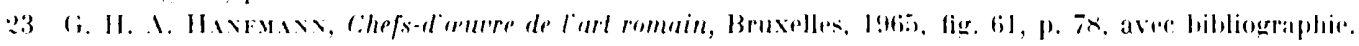




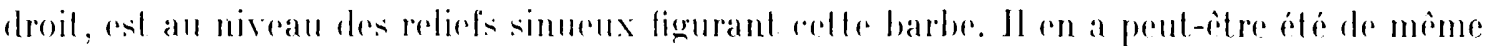

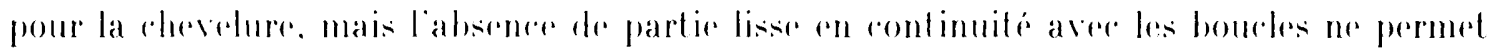
pas d'en juger aussi aisement. I) autre part, si la stylisation celtique est particulierement aceentuée dans les masques de Wontsérié el du Vieil-Evreux -.. notamment par les hourles en spirales régulieres de la rhevelure -... la tête du Mont-Berny présente une tendance incontestable au réalisme. of les bustes d Augst el de Varnheim une plastique fortement influencée par l'art romain. lanst entere les deux extremes que se situe notre tète de cienainville. sichémalique du lait de l'habileté limité de son auteur, elle ne présente de stylisation que l'on puisse ratlacher à une tradition celtique que pour les meches de rhevenx en boutons encarlant le front tres proches de celles que lon retrouve sur les tides fémininese en bronze coulé de La Croix-saint-0uen 12, 13\% ou encore. aver une stylisation plus

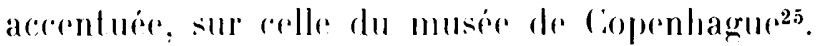

Ajoutons que la simplicite dexécution de la tête de Cienainville est également marquée sur le plan comparalif par l'absence d'essai de figuration des sourcils ou des cils, tels qu'on les observe sur les masques de la force de brotonne sourcils au repoussé). de llontsérié

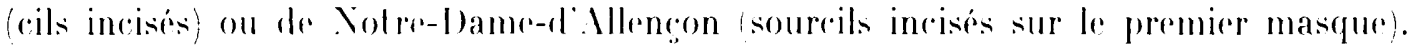

Que represente cette libre ou plutoit quelle intention l'artiste local a-t-il cue en la laconnant? Peut-on penser ì un personnage réel, à un portrait ? Il serait sans doute peu ressemblant étant donné la simplicite du travail, mais ce n'est pas une raison pour écarter

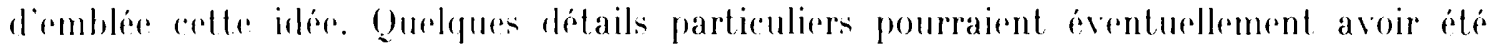
figures pour cola : la harbe at la moustache. fes bourles de la chevelure si elles ne sont pas simple trait de tradition celtique. . la cuirasse si l'on retient cette interprétation. Les détails qui viemnent d'itre rappeles ont conduit certains a proposer une identification : Hardrien. Vous nous bornerons a mentionner ceotte proposition. sans penser posséder d'arguments suffisants pour la soutenir. Pourrait-on, a defaut de la proposition préédente, voir dans rette tete celle d'un personnage important de mème époque ou d'une époque un peu postéreure, respertant la mode rapillaire en vigueur a Rome ? La présence d'une cuirasse devait sans doute conduire i une interprétation de ce genere mais on a verombien cetter présence est pelu assurée.

Ne faut-il pas alors rattacher plutrot la tiste de cienainville a la série de pièces auxquelles nous la arons comparér précédemment sur un plan principalement technique a ces masques de raractere cultuel. mais différents des "representations divines habituelles" el dont la "drestination exarte reste ... mystérieuse $\|^{26}$ ? Comme la plupart des masques dont le contexte general de déecourerte rest ronnu, notre tète dre (ienainville a bien été trouvé sur un site et dans les vestiges deun batiment de raractere religienx. Il ne serait done pas anormal qu il puisse sagir de la representation d'une divinite. Mais pas plus que pour les pieces de comparaison. il ne parait possible de donner un nom a cerlle-ci. Ce qui nous semble,

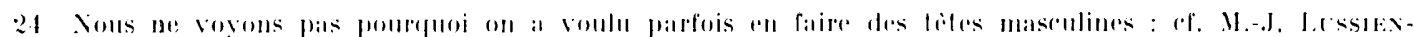

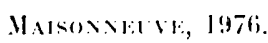

25 Vieir II. 11 $i$.

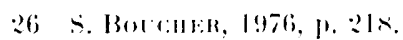




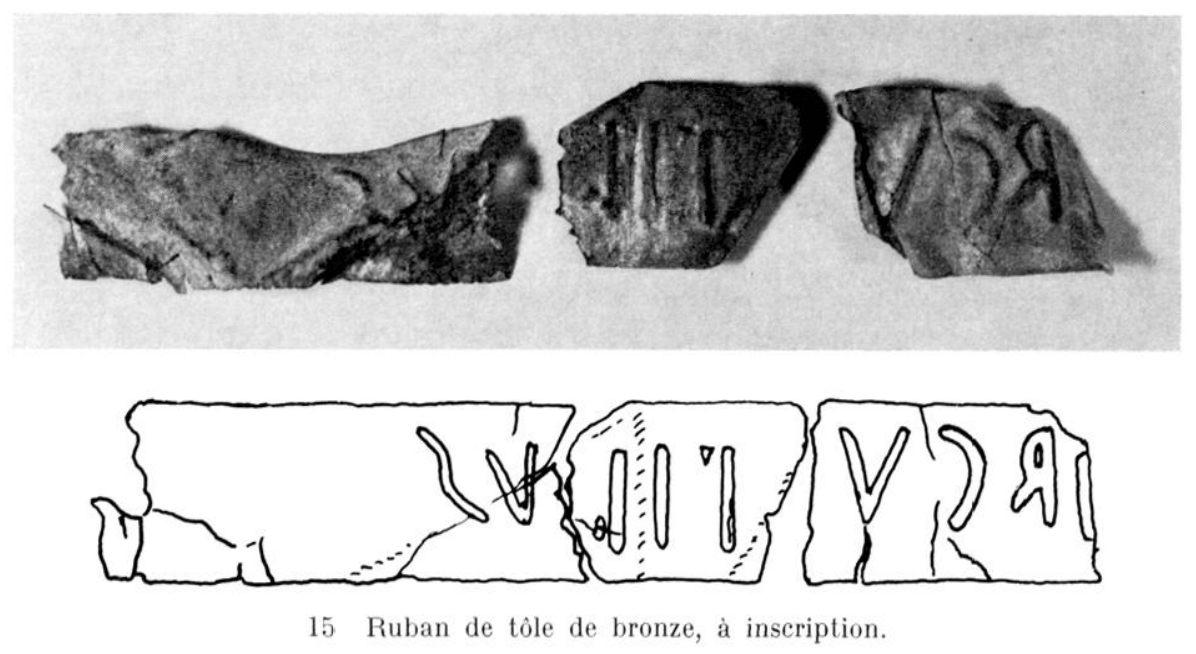

en tout cas, à souligner, c'est que la pièce a dû constituer un objet votif et non la figure de culte ; on concevrait mal en effet, dans le cadre architectural bien romain que constitue le bâtiment où la dérouverte a eu lieu, la présence d'une figure de culte d'une facture aussi peu classique ${ }^{27}$.

Une autre découverte, faite en 1980, dans le périmètre du mème bâtiment, mais à quelque distance de la tète (environ $4 \mathrm{~m}$ ) est, d'ailleurs, peut-ètre à mettre en relation avec celle-ci ; il s'agit d'un ruban de tôle de bronze très mince de $1,7 \mathrm{~cm}$ de largeur et environ $10 \mathrm{~cm}$ de longueur, malheureusement incomplet, en 3 fragments se raccordant, plus ou moins fortement pliés, sur lequel on lit l'inscription suivante :

\section{- - IRGV I'II. VS}

Les lettres exécutées au repoussé ont $0,9 \mathrm{~cm}$ de hauteur ; pour les avoir dans le sens normal de lecture, il faut les regarder en creux, alors qu'il paraitrait plus satisfaisant techniquement de les regarder en relief (c'est d'ailleurs sous cette dernière forme que le document est le plus lisible actuellement) (fig. 15). Cies lettres rappellent étroitement par leur mode d'exécution les petits bàtonnets qu'on observe sur la partie antérieure du cou de la tête de bronze et qui ont pratiquement les mèmes dimensions que les hastes de l'inscription. D'où le rapprochement évoqué précédemment. L'inscription - qui comporte un $\mathrm{F}$ et un $\mathrm{E}$ archaïques -.. se développe aisément ainsi :

$$
\text { - - ircu fe(cil) v(olum) s(olvil) }
$$

Le premier mot, incomplet, correspondrait au nom du dédicant, peut-être le personnage qui avait commandé et offert la tête. Dans cette hypothèse, on aurait là une inscription comparable à celle figurant sur le buste-«masque " trouvé aux environs d'Érreux ${ }^{28}$ et qui aurait pu avoir été fixé, sous la tête ou plutòt le buste , sur le support de bois.

27 On a d'ailleurs la preuve, d'apres les nombreux fragments recueillis dans la fouille du Temple et du Bàtiment secondaire VIII, de l'existence, dans l'un ou l'autre de ces édifices, de statues en fonte de bronze de facture classique.

28 Voir n. 10 $f$. 
Rerste la question de la datalion. Tromvere dans les vestiges d'un batiment dont la construction parait remonter au milieu ou au troisimme quart du ne siecle et la destruction au deuxieme quart du rve, la date du depot de la tête se situe ent re ces deux dates extremes:

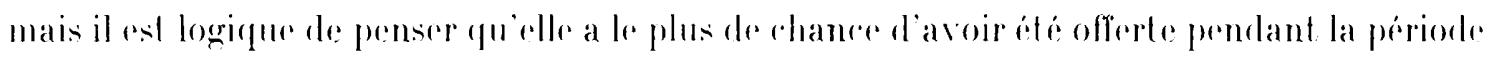

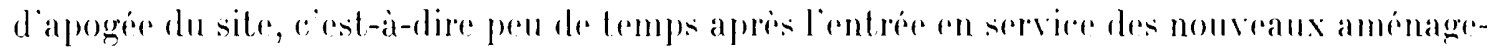
ments de celui-ci, dans la denxieme moitie du ne siècle.

Cette datation se troure rejointe par ende que permet d'envisager la composition du metal. II. France-tanord voir annexe I) sugrerere. en effet, que le metal ayant sorvi a la fabrication de la lite pourrait provenir de la refonte de monnaies ef observe que sa composition est proche de cenle des sesterese at dupondii de la période 160-190, drapres

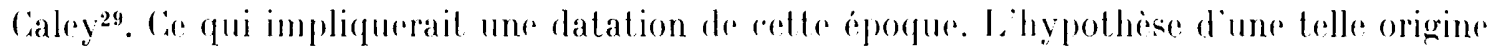
du metal na rien d’inraisemblable. Lin ee qui concerne sa ronséquence chronologique, nous ajouterons simplement qu il faut élargir la datation jusculau début du no" siècle, l'une part pare que pendant cette période la composition du métal est encore proche de celle de la periode précitén: d'autre part en raison de la notion de lerminus post quem, habiturle en matiere de datalion par des monnaies; il faudrait aussi supposer que l'artisan a choisi dans la circulation des monnaies de la période considérée de preférence à d'autres

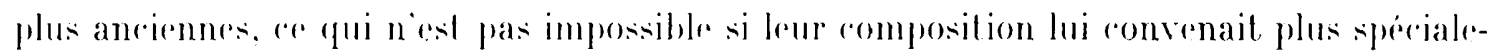
ment.

Indépendamment de redte hypolhese, les analyses de bronzes figurés effectués depuis

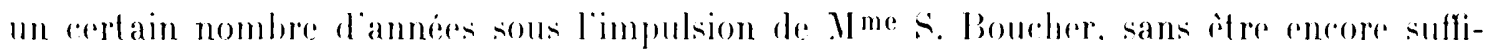
samment avancés pour alteindre des résullats définitifs et valables pour toute la ciaule,

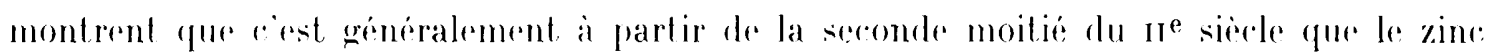
apparait, dans des proportions d'ailleurs variables, dans la romposition des stabetles et autres objets provenant de Gaule ${ }^{30}$.

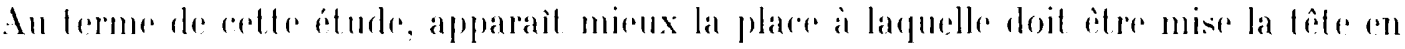
loble de brenze de Genainville parmi les sculptures en métal relevant de cette technique que leur facture ot leur coprit imposent de considerer comme des aures de tradition gauloise (ou plus généralement celtique). Le fait qu il sagisise de décousertes le plus souvent anciennes, rend la datalion de relles-ci hasardeuse. Sauf ras de découverte isolée dlien de Bouray), les sites de provenane sont connus essentiellement par des vestiges d'époque romaine. de sorte que le classement à l’époque de l'Indépendance de certaines d'entre alles, qui sont dinne stylisation celtique particulierement marquée (masques de Montserié of du Vieil-Fureus . reste sujet à caution. Pour d'autres au contraire, trourées en principe

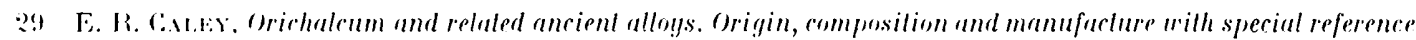

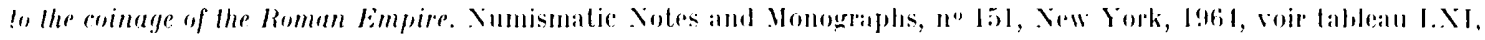

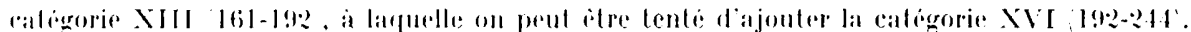

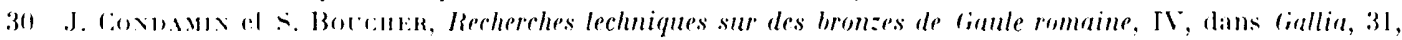

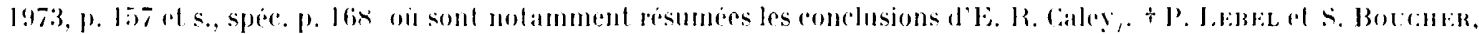

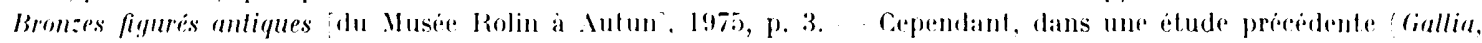

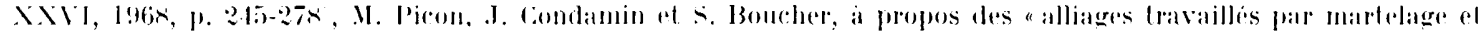

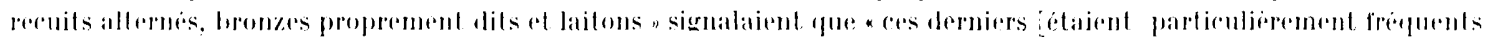

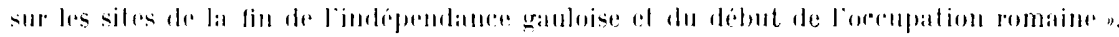




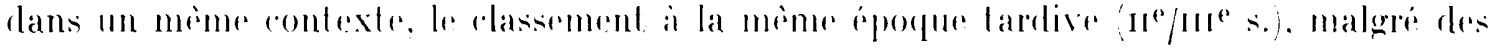
différeneres stỵlistiques importantes, surperne masques en arogent de Notre-l)ame-d Allencon).

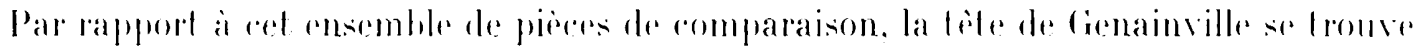

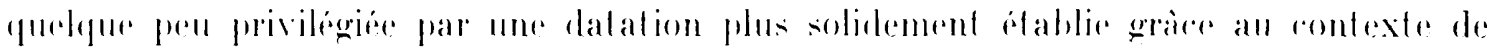
découverte corrobore par la composition du métal. Par son caractere de lite complete

en fait probablement un buste a lorigine elle apparait, dans leetat actuel de la documentation. comme une piece juspüiri unique. (Eurere d'un artisan local, elle se rattache a la tradition celtique. plus par sa terehnique ed par la rudesse de sa plastique que par une certaine stylisation a laquelle ne peut itre rattarhé que la figuration des boucles de la chevelure. On notera que eette tradition est également attestere ci cienainville par la décou-

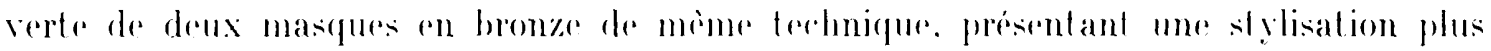
marquée et vraisemblablement plus anciens.

Ainsi sur ce site orné de monuments publies typiquement romains dans leur mode de ronstruction et leur decoration architedurale. voulu pense-t-on comme foyer de romanisation, le vieux fonds indigène continue, dans la deuxieme moitié du $11^{\mathrm{e}}$ siècle ou

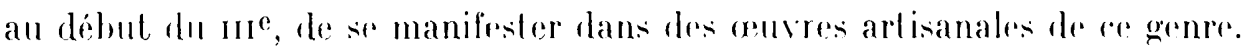

\section{Pierre-Henri MrTakn}

(C.N.R.S.)

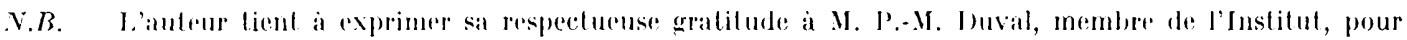
ses conseils of l'orientation du'il a bien voulu domer a cefte recherehe. Il exprime ses sinceres remerciements pour

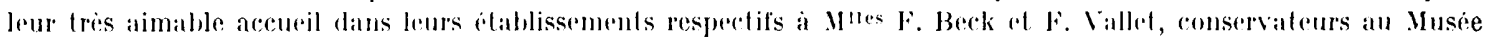
des Antiquites nationales, a . V. F. Baralfe, conservateur au Vusie du Jouvre, ainsi que, pour les renseignements ou documents gu'ils ont bien voulu lui fournir, à .y me s. Boucher et ylue C. Bimont, maìtres de recherche au C..N.R.S., a MII. R. Agache, direcleur des Antiguites prehistoriques de Picardie, (i. Boon, conservateur au National Museum of Wales Cardiff, (x. Dufour, responsable des foutles de Vendenil-caply, ll me E. Chirol, conservaleur du Musée

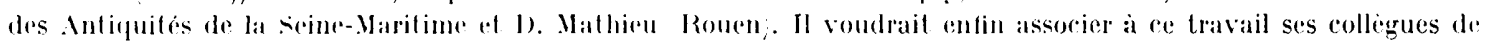

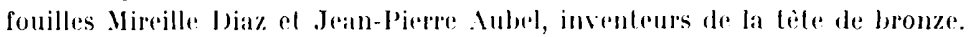




\title{
ANCENES
}

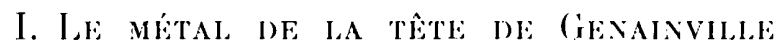

Des examens métallographiques ont été faits sur trois petits échantillons prélevés sur les fragments de la tète : un clou, un fragrment de clou et un petit fragment de tête, un fragment de tête. L'emplacement original de ces fragments n'est pas défini avec certitude.

L'examen métallographique montre qu'il s'agit d'un métal bien élaboré, de couleur jaune d'or, légèrement rosé, présentant la structure d'un laiton plus ou moins écroui.

Divers essais, lant micro-chimiques qu'électro-colorimétriques (électrotest) confirment la présence de zinc. Quelques essais ont été faits sur le mélal (á l'envers) el montrent que l'alliage est. légèrement variable d'une plague à l'autre et qu'il s'agil d'un alliage cuivre-étain-zinc avec des Leneurs en zinc de l'ordre de $10 \%$ el d'étain inférieures a $10 \%$, probablement 5 à $8 \%$. Cet alliage est plus proche du laiton que du bronze, se travaille bien et posise une belle couleur roisine de celle de l'or. Il se rencontre dans le monnayage romain, sesterces et dupondius de la fin du $\mathrm{ni}^{\mathrm{e}}$ siecle. d'apres Caley, soit entre 160 et 190. Ces laitons étant en revanche tris rares en Gaule ou les minerais de zine sont pratiquement inconnus a cette époque, on peut admettre une origine élrangère du mítal, ce qui ronduit a penser au remploi de monnaies romaines.

Le poids total de la tète était de l'ordre de 500$) \underline{g}$. les plus grands morceaux pesant au maximum 200 g. Si l'on armet que le métal utilisé provient de monnaies fondues, il aurait sulfi de quelque vingl sesterces pour obtenir la masse nécessaire.

Les clous faits de tòle roulée semblent plus riches en zinc (d'aprés la couleur). L'état de corrosion du métal, surtout à l'intérieur oì les tests ont été faits, ne permet pas une meilleure approximation des teneurs en rinc et étain.

1. France-Ianomil

\section{Les CIOUS TUBCLARES DE IA TÊTE DE GiENANVILLE}

Les clous tubulaires qui se répartissent sur certains points de la tête de laiton ne peuvent, ètre considérés comme étant placés uniquement dans le but de renforcer les raccords soudés a l'étain des différents éléments de construction. Si celte fonction avait été retenue, il aurait été plus commode et simple d'employer des rivets tubulaires cylindriques, plutôt que des clous còniques dont l'allongement ne peut fournir aucune retenue dans le métal. Pour que cette retenue existe, il convient que la pointe s'engrage dans un matériau mou mais résistant (exemple : bois de sapin). A noter que le còne des clous n'est ni tordu, ni déformé, et que seules leurs extrémités sont écrasées fortement à la surface du buste.

Il s'agit donc de chevilles clouées, maintenant les tòles sur un châssis quelconque, et non de rivets d'assemblage ou de renfort. Les reconstitutions effectuées l'ont été avec l'aide des matériaux 
suivants : les clous ont été exécutés en laiton de :3/10 de millimètre d'épaisseur, d'après les originaux et suivant le procédé décril plus loin. Pour représenter la tỏlerie de la tèle, il a été également employé du laiton de $3 / 10$.

Les clous préparés sont enfoncés de la maniere suivante : une pointe de fer carrée (poincon! est placée à l'endroit ou l'on désire ficher le clou. Ia tòle doit porter fermement sur un support résistant mais mou exemple : bois de sápin). En frappant sur la tête de la pointe carrée, les tỏles se perforent en produisant une petite bavure par-dessous (débouchure). On continue à enfoncer la pointe carrée jusqu'à l'instant où l'ouverture de la tòle et le trou dans le bois peuvent permettre de placer le clou de laiton, mais il convient que relui-ci déborde encore d'environ un quart de sa longueur. A noter que l'extrémité de la pointe carrée doit être plus obluse que son corps, ce qui laisse un peu de bois non foré au contact de la pointe du clou.

On retire la pointe carrée en la faisant pivoter sur elle-mème. ce qui a pour effet de produire une perforation pratiquement circulaire el de faciliter le dégagement de cette pointe. Le clou étant placé dans l'ouverture (avant-trou , on le frappe doucement au marteau afin qu'il vienne s'enfoncer définitivement dans le bois et que son corps vienne prendre appui circulairement dans l'ouverture des tôles. La partie qui dépasse est écraséc de façon à former une lète grossière mais peu saillante.

A noter que si l'on voulait perforer les tòles sans support, inlérieur, il se produirait un sérieux enfoncement avant toute pénétration. Dans le cas où un tas creux (tubulaire) serait placé sous les tòles, il est peu probable que le poinçon rencontre aisément le creux du tas, aucun repère n'étant possible. Surtout dans le cas d'une tête dans laquelle la main rentre tout juste.

I a résistance d'un clou lubulaire cônique est suffisante pour qu'il puisse ètre enfoncé dans un bois de sapin. sans avant-trou, à la condition que le bois soit recouvert d'une tòle percée par avance, si l'on veut former la tête du clou. Cependant el dans ce cas. le còne du clou se resserre sur lui-mème entre les fibres végétales et devient filiforme. Cela n'est pas le cas pour la tèle de Genainville, les clous d'origrine étant encore parfaitement coniques.

Fabrication des clous: reconstitution. Pour fabriquer le clou cònique, tubulaire el à recouvrement non soudé, il convient que l'ébauche soit faite d'une tòle triangulaire. Cependant, après observation des originaux et divers essais de mise au point, nous avons remarqué que seul le triangre rectangle convenait parfaitement : lorsque le còne est roulé, une sorte de languette déborde a la base du còne. G'est cette languette qui, repliée, constilue la partie essentielle de la tête du clou après mise en place. Pour l'opérateur qui possède de la tòle toute préparée, il est plus aisé et plus rapide de fabriquer des clous tubulaires que des clous massifs. Il faut environ de une a deux minutes, a partir de la tôle découpée en triangle, pour rouler parfailement un clou.

Mode opéraloire. Nous avons préparé des ébauches dont les mensurations correspondaient a la majeure partie de celles des clous d'origrine. Des tòles reclangulaires de $23 \times 17 \mathrm{~mm}$ sont recoupées suivant une ligne définie par l'hypoténuse. On obtient ainsi, et pour chaque plaquette, deux triangles rectangles qui sont roulés chacun sur un petit mandrin cònique effilé, du grenre pointe à tracer. L'outillage nécessaire est très restreint, puisqu'il suffit d'un mandrin, d'une petite pince à becs ronds et d'un petit marteau, pour former aisément le clou sur un tas plat.

Les chevilles de laiton en forme de clous tubulaires cóniques qui tapissent la surface de la tête de Genainville ne peuvent avoir été primitivement placés en vue de renforcer les assemblages soudés a l'étain. Elles sont manifestement mises en place postérieurement à la fabrication de la tête sur un chàssis (de bois), mais vraisemblablement après dessoudage ou rupture de soudures, sur certains éléments, ce qui a pu permettre la mise en place du rhassis.

Aucune trace de bois n'a été rencontrée au cours des études et remise en état de l'objet. On peul, expliquer cet élat de choses par le fait que depuis un certain temps les éléments de la tète ne se tenaient en partie ensemble que gràce aux chevilles clouées sur le chàssis. En supposant une destruction partielle avant l'enfouissement, le bois a pu être séparé assez tòt du laiton et ne pas laisser 


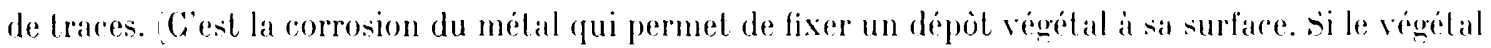
est élimine avant corrosion. il n'en subsiste aucune trace.

Le chàsis devait ètre fait d'un élément vertical, qui s'enfonçait jusqu'au sommel du crine (clou a cet endroit), avec seulement quelques plaques de bois rapportées et venant s'appuyer sur la tòle, a l’intérieur de la tète (roir la disposition générale des clous . Celle disposition devail permetıre au bois d’ètre éliminé avant la corrosion du métal. La mise en place en deux temps de la tête sur un nouveau support serait également démontrée par le fail d'yeux ne faisant pas partie d'un premier monlage.

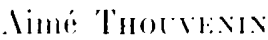

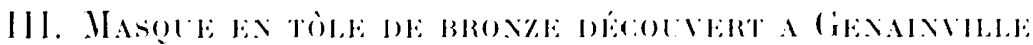

la fragment a ete découvert on 1965 pris dre la lacarle est du lemple. partie nord

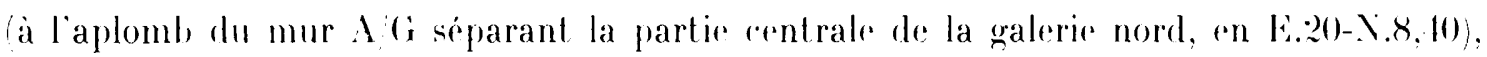
au-dessus du niveau du sol de service du lemple, mais dans une couche houleversere lors

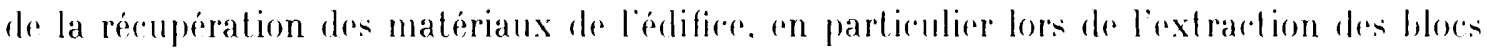

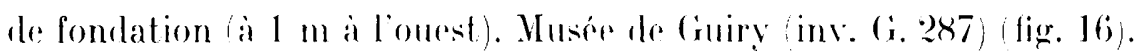

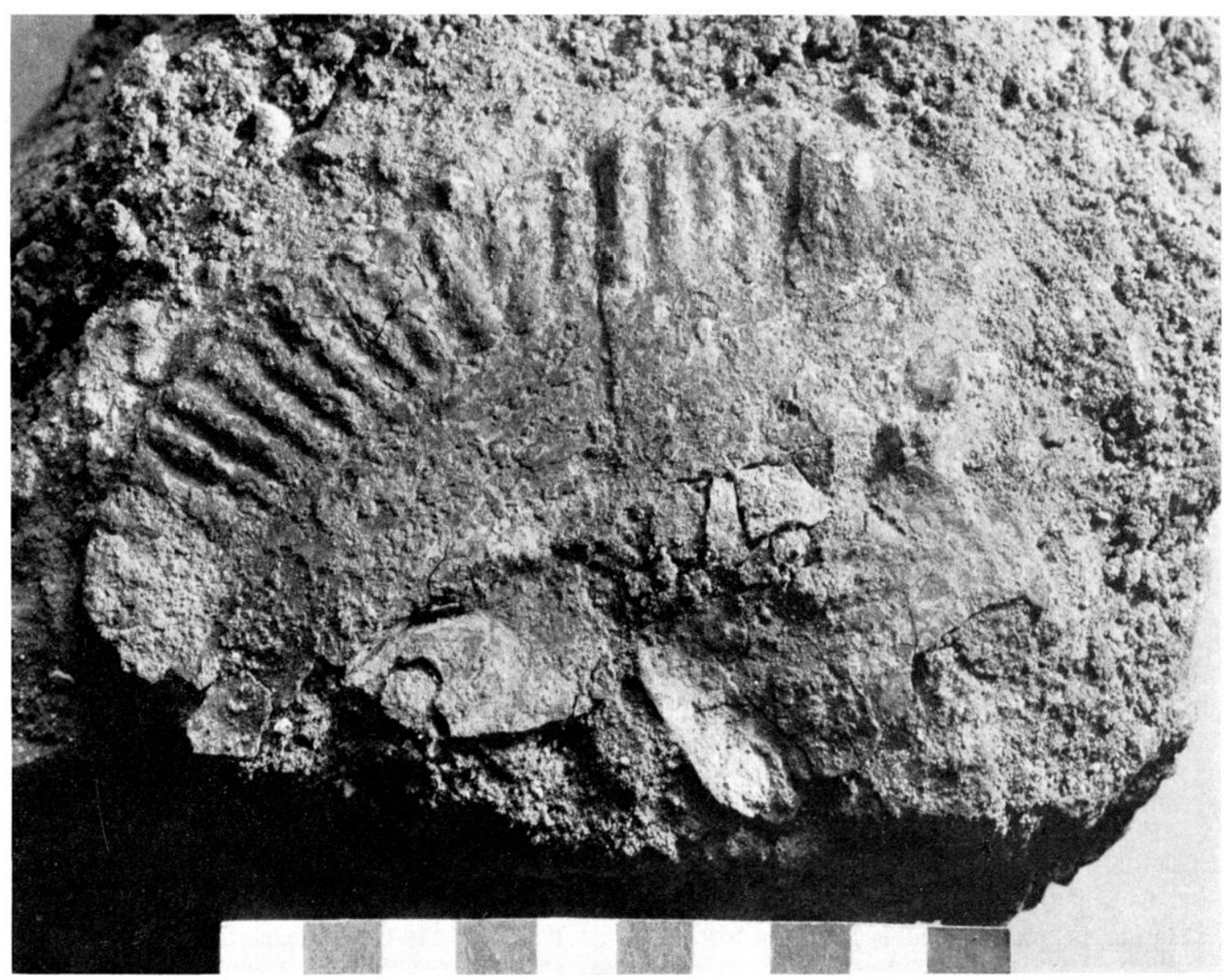

16) Cienainville. Parlio superimes de masque, an moment de la decouverte. 
Il s'agit de la partie supérieure d'un masque humain. probablement masculin. un peru plus petit que nature. Largeur restituee au niveau des yeux : $0.13 \mathrm{~m}$. La cherelure est figuré par des miches raides réaliseres au repousse de lonterieur, présentant une orientation légerement oblique par rapport a un axe médian et alteignant le bord de la pièce. Les yeux dapres le droit. seul observable de facon sime sont figures par un tracé ovale en creux, cernant une surface bombere pereée d'un trou rond a l'emplarement de la pupille-iris. ce

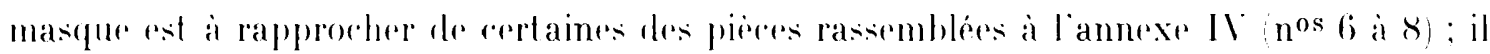

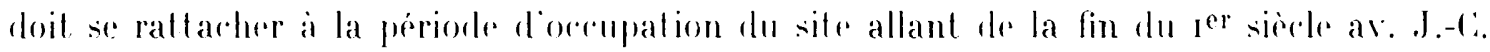
ant délut du $\mathrm{II}^{\circ}$ simente.

IP.-II. II.

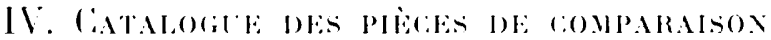

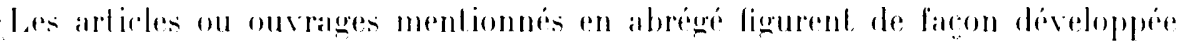
dans la bibliegraphlie donnese in finej

a) Masiques. lites el bustess en tile de bronze.

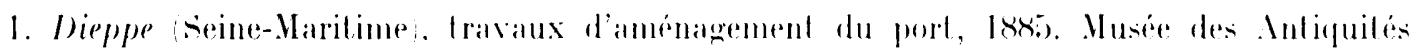
nat ionales, siant-fiermain-en-Laye, inv. 29.609. Part ie posterieure environ le liers arriere d'une liste masculine. Haut. : $0.30 \mathrm{~m}$ (tigr. 17 .

La figuralion des mèches de la rhevelure vient jusqua l'extrème berd de la piece. Au niveau inférieur du cou, du coté gaurhe, la tìle régulièrement découpée ailleurs, comporte un prolongement, sorte de lanquette de $4 \mathrm{~cm}$ de largeur et quelques centimit res de longueur dérhiquetée à son extrémité et repliée vers l'intérieur) qui devait concourir a l'assembliage; une languelte semblable devait exister du coté droit. Pas de traces pour clous ou rivets. ni traces de soudure. Mais a la batse du rou. l'intérieur conserve, sur $4 \mathrm{~cm}$ de hauteur. une mal iere grisal re bien cialée sur toute la largenr. ayant dù servir a la fixalion sur un sorle. Au niveau de la nuque, deux mierhes de cheverux sont enroulées en spirales.

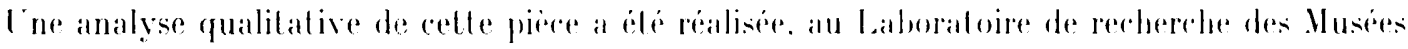

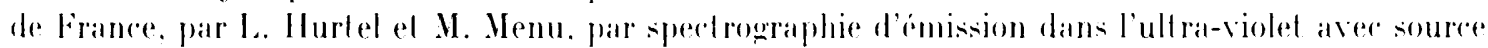

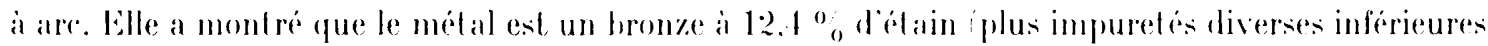

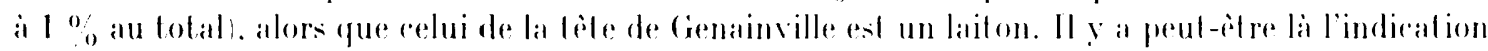
d'une difference ehromologique.

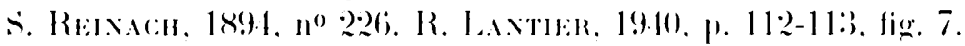

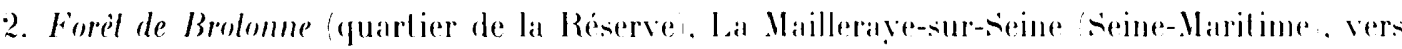

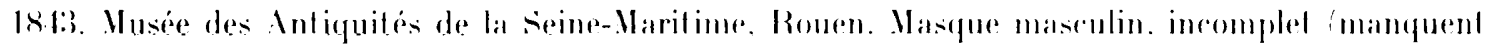
colé droit et les parties basses. Haut. maximale artuelle : $0.11: 3$ m : epais. de la loble : de 0.00601 i 0.00018 m $m$ (fig. 18).

Le métal est coupe de facon réguliere horizontalement au nivean du sommel du fronl et verli-

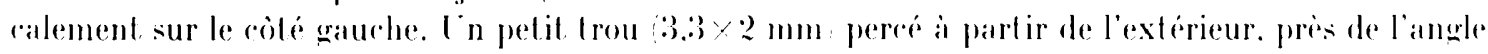
ainsi détermine. devait servir à la fixation sur une àme de bois. (on peut imaginer une pièce rapportée pour la figuration de la cherelure ou d'une coiffure.

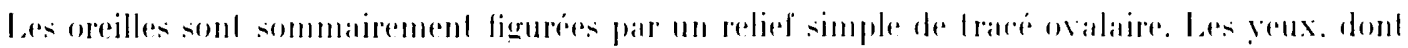

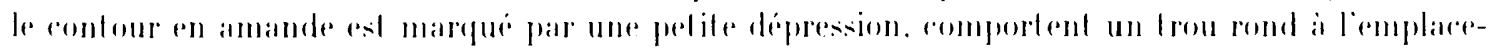

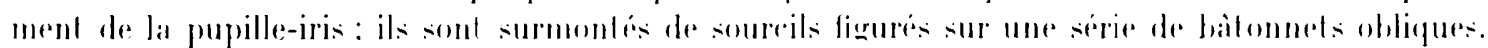




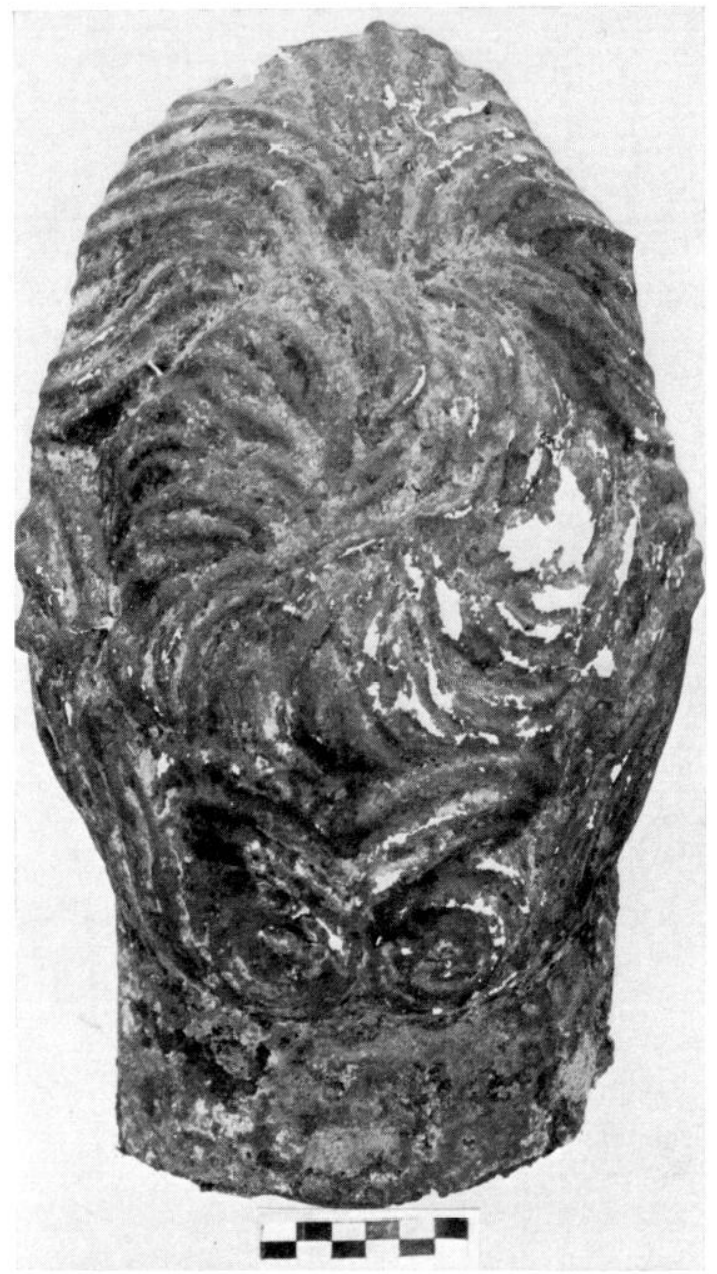

17 Dieppe. Partie postérieure de tèle.

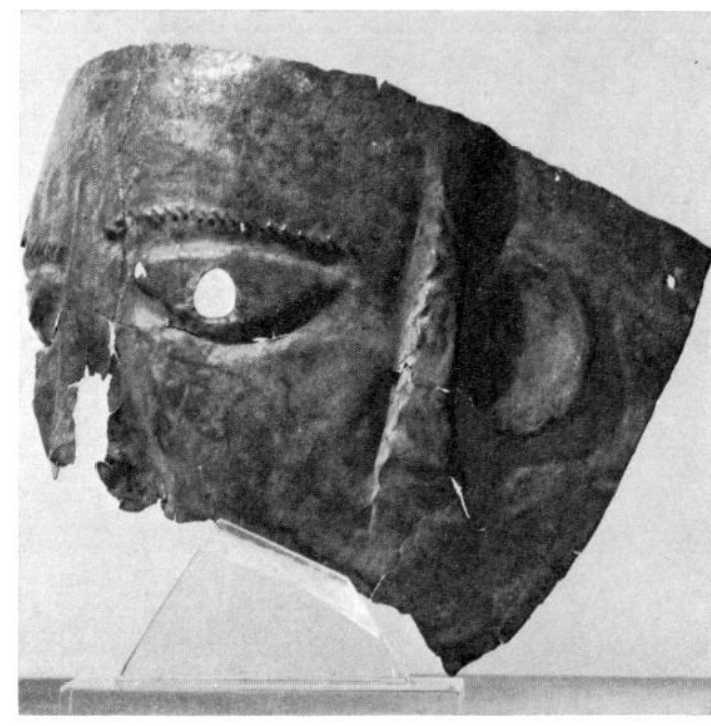

I8 Forêt de Brotonnr. Masqur masculin.

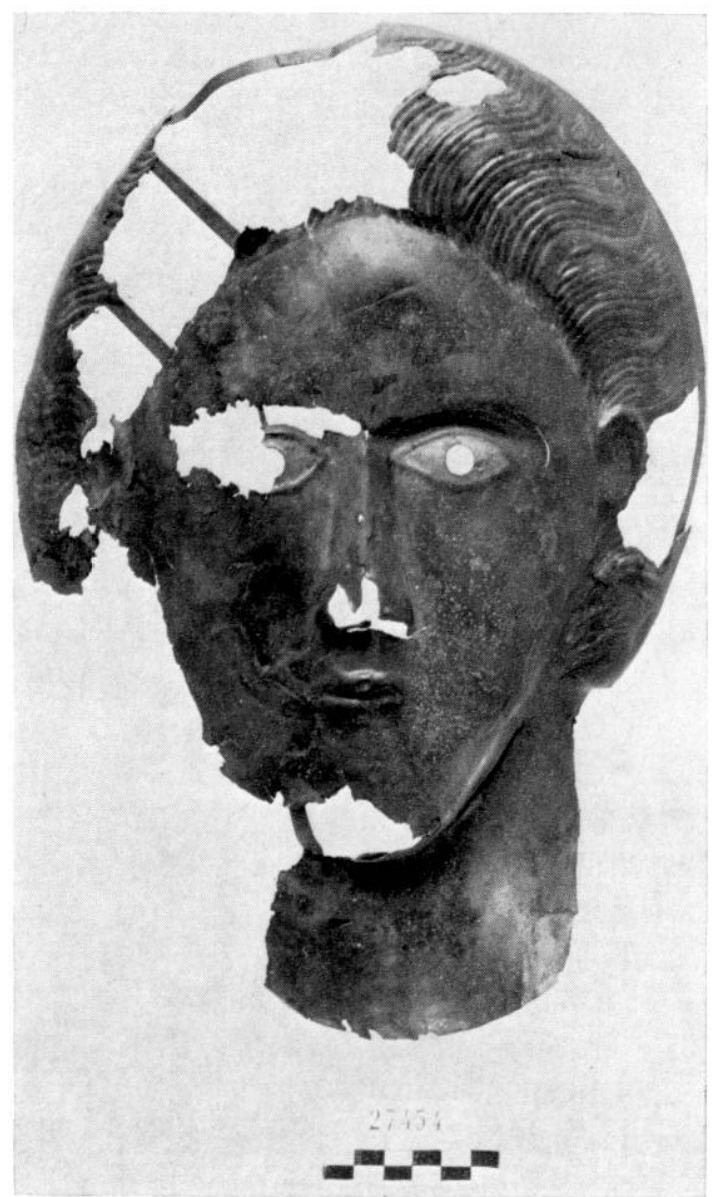


Entre l'oreille et l'œil gauches (seuls conservés), on remarque une bande verticale en relief ornée vers l'avant d'une série de petits arcs eux-mêmes en relief.

Léon Courril, Archéologie ... du Département de l'Eure, V. Arrondissement de Pont-Audemer, 1925, p. 96-97, fig. (prov. indiquée Le Landin, Eure). Marie-Clothilde Lrocoy, La Forèt de Brotonne à l'époque gallo-romaine. Inventaire archéologique, mémoire de Maitrise, Fac. des Lettres et siciences humaines de Rouen, 1975, p. 131-132 et pl. XXXIII, nos 1 et 2. Guy V:rrox, L'art cellique en IIaule-Yormandie à tralers les collections du .Musée départemental des Anliquités de la Seine-Marilime. Actes du Colloque international d'Archéologie. Centenaire de l'abbé Cochet, 1975, p. 353-357.

3. La Croix Saint-Ouen (Oise), vers 1873. Musée des Antiquités nationales. Saint-Germain-enLaye, ins. 27454. Masque féminin avec cou. Haut. : $0.333 \mathrm{~m}$ (tête seule avec la cherelure $: 0,27 \mathrm{~m}$ ); épais. de la tòle: de 0.0004 a 0.0005 m (fig. 19).

La figuration de la chevelure ne va pas jusqu'au bord de la pièce. mais s'arrète d'une façon assez irrégulière. La bande lisse qui en résulte ne paraît pas destinée à permettre le raccordement avec une pièce occipitale. Le masque s'arcorderait mal avec un tel complément : la pièce est asse\% plate, elle présente un relief de $0,07 \mathrm{~m}$ au maximum, et le bord tend a s'évaser ; le cou est loin de former le demi-cylindre. Les yeux, dont le contour en amande est marqué par un petit relief, sont argentés ou étamés (leur couleur tranche sur le gris jaunâtre du métal brut) et comportent un trou rond à l'emplacement de la pupille-iris.

A. de Rovcy, 1884, no I. S. Reivach, 1894, no 227. R. Lastier, 1940, p. 109 et fig. 4. F. Braemer, 1968-1969, $2^{\mathrm{e}}$ part., p. 82 et $\mathrm{n}^{\circ} 6$.

4. Le Vieil-Evreux (Eure), fouilles Bonnin (vers 1840), dans la "basilique" (en fait ensemble de temples). Muscé d'Évreux, inv. 4835. Masque masculin. Haut. : 0,235) m, larg. : 0,260 m.

Le cou est remplacé par une collerelte, ornée dans la partie inférieure d'une rangée de petites bossettes séparées de barrettes verticales. La chevelure, presque entièrement disparue, était figurée par des spirales; elle venait très normalement au-dessus du front. Les yeux, aux orbites évidées, sont légèrement obliques. La bouche est close. Bien que se rapprochant par divers détails du masque de Montsérié, la stylisation celtique y est moins accentuée. La pièce est en mauvais état et très aplatie. Elle est percée de 7 trous carrés forés de l'intérieur (métal soulevé par l'enfoncement de la pointe), répartis de façon anarchique sur le visage. Etant donné cette répartition, il parait difficile qu'ils aient pu servir à la lixation sur un support de bois. C'est peut-être le sens de forage de ces trous qui a amené la figuration erronée de la pièce (inversée, intérieur pour extérieur) dans les premières publications. Ce masque "viendrait peut-être établir le lien avec les ouvres de l'archaïsme grec ou étrusque" (\$. Boucher); par sa découpe, il rappelle curieusement le masque mycénien dit "d'Agamemnon".

Th. Bonvix, Antiquités gallo-romaines des Eburoviques, Paris 1860), pl. XXVII. O. Brnvdorf, p. 37 et fig. 3. L. ColtiL, Archéologie du lépartement de l'Eure, IV. Arrondissement d'Éureux, 1921,

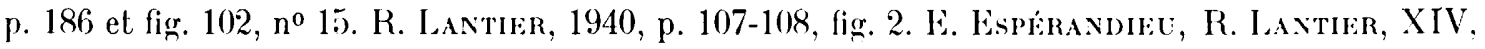
1955, no 8325. F. Brafmer, 1968-1969, $2^{\text {e }}$ partie, p. 82, no 3 et fig. 39. S. Boucher, 1976, p. 38-39.

5. Le Monl-Berny, Saint-Étienne, canton d'Attichy (Oise), fouilles A. de Roucy, dans le temple. Musée des Intiquités nationales, Saint-Germain-en-Iaye, inv. 13898. Masque féminin avec cou. Haut. : $0,165 \mathrm{~m}$; épais. de la tòle : $0,0005 \mathrm{~m}$ (fig. 20$)$.

La figuration de la chevelure s'arrête à l'arrière à $0,007 \mathrm{~m}$ du bord de la pièce, laissant une bande lisse, qui a pu ètre réservée pour permettre le raccordement avec une pièce occipitale pour former ainsi une tête complète. Les yeux comportent un trou rond a l'emplacement de la prunelle. Les paupières sont figurées, de façon assez naturelle, en relief. La bouche et les cheveux sont bien modelés.

V. Cacchisi:, Description des fouilles archéologiques exéculées dans la Forêt de Compiègne sous la direction de .Y. A. de Roucy, I, Compiègne, 1900, p. 40 et 51. S. Reinach, 1894, no 222. R. Lantien, 1934, fig. 18b ; 1940, p. 109, fig. 3 et p. 107, 113 (et n. 1), 114 (et n. 5). 


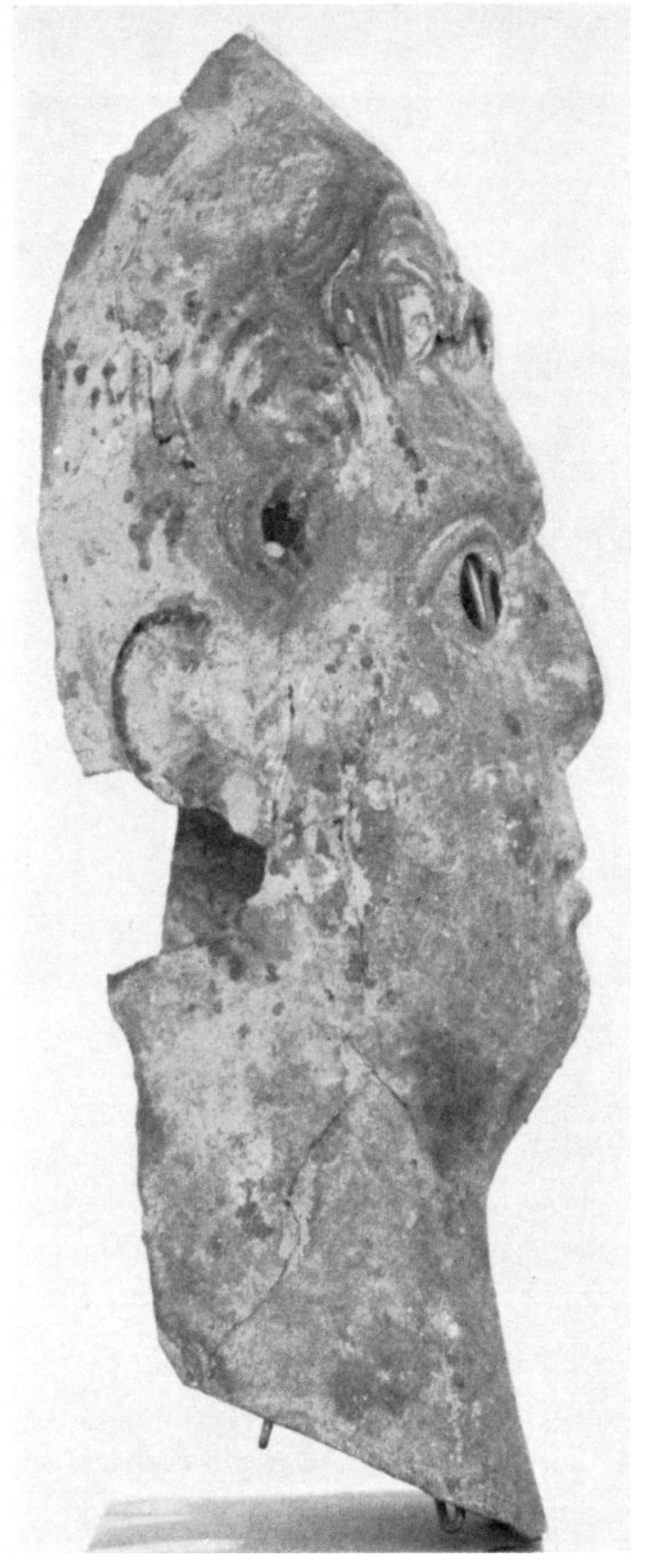

20 Ja Mont-Burny. Masque fiminia.

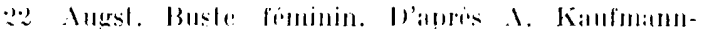
Heinimann, lie romisthe Bromsen der schweiz. .

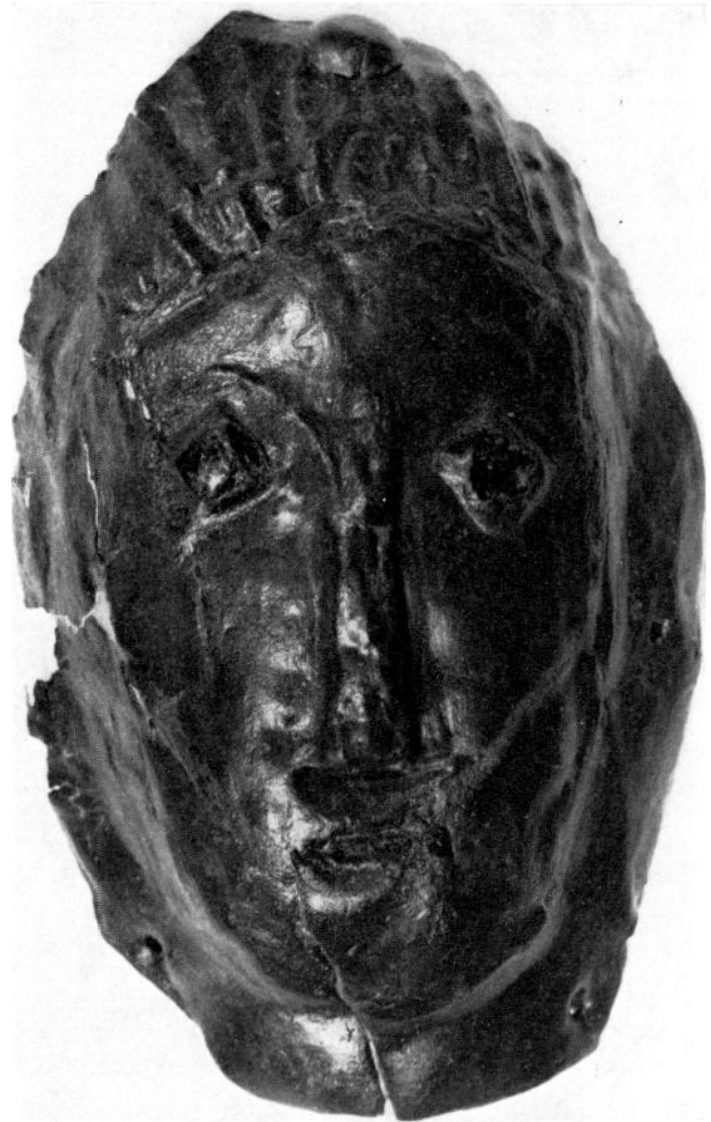

?l Vendeuil-daply. Masfue féminin.

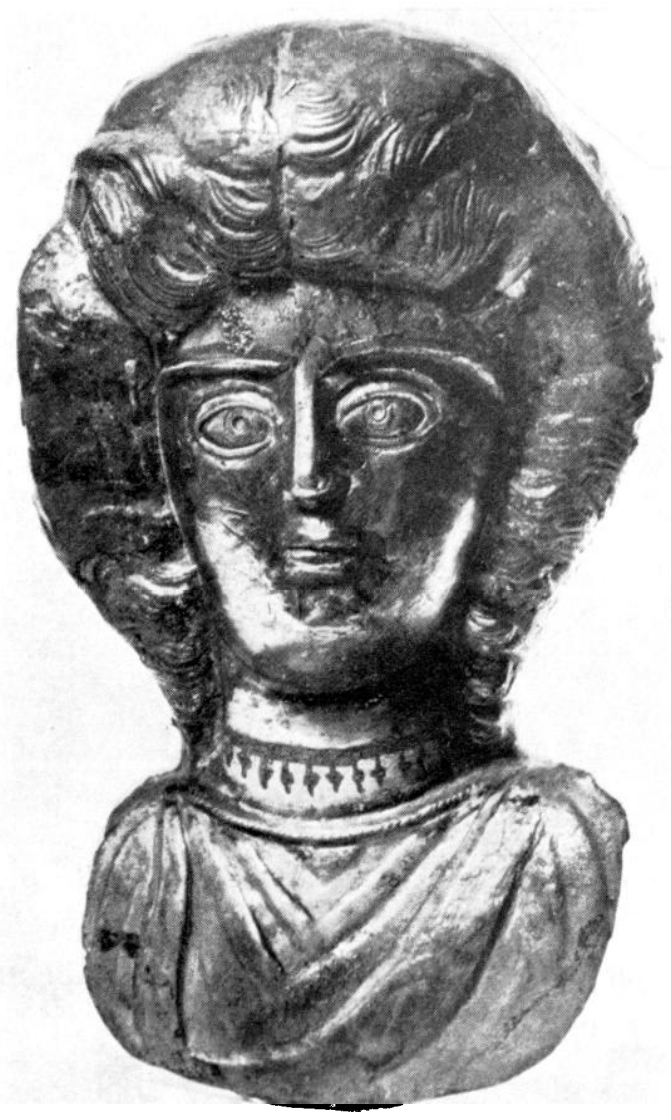




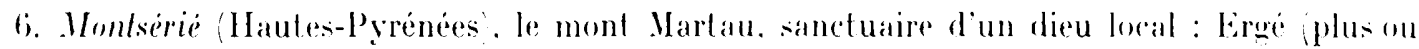
moins assimilé a Mars ; fouilles xaxe siecle 18:39?. Muser Massey. Tarbes, ins s7l. Moulage au Musée de saint-Germain. Masque matsculin barbu, aver cou en forme de douille. Hant. : 11.17 m; épais. de la tóle : $0.0008 \mathrm{~m}$ (de 0.000 .15$)$ à $0,001 \mathrm{ml}$.

le bord de la piece. sur la partie arriere conserve au nivean inferieur à quarehe pour lobservaleur, présente une bande lisse de $0.006 \mathrm{~m}$ de largeur, interprétée par certains comme ayant dì etre destiné a permette le racoordement aver une piece ocripilale ; la surfare lisse se trouve au niveau des reliefs de la figuration de la chevelure el non an niveau des rerex, comme on sy allendrait plutiot dans l'hypolhese qui vient d'etre rappelóe. La figuration se caractérise par labsence de front. une chevelure formant bourrelel aulour du visage de spirales enrouleses allermalivement dans un sens el dans l'aulre, des yeux disposes en obliques dont les orbites vides sont bordés diun petil

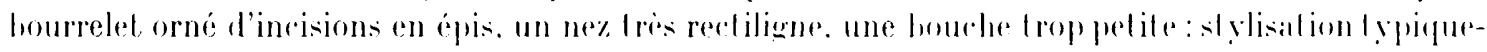
ment cellique qui a conduit a une datation anterieure a löpoque romaine fien que le rontexle de decouverte apparaisse comme plus recent:

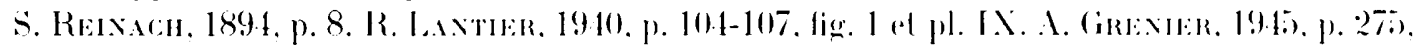

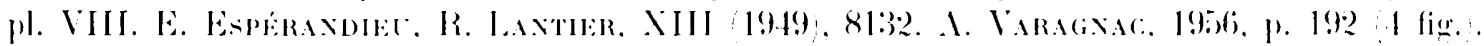

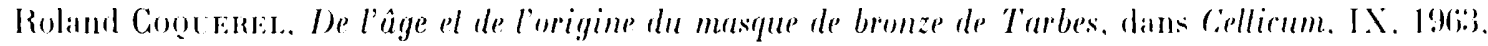

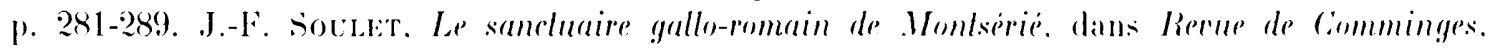

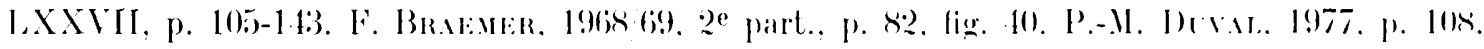
liw. 97. s. Borcher, 1976, p. :38-39.

7. Reims Marne? Incienne collection de Lestrange: lien de ronservalion arluel inconnut " Masque viril ... de type gaulois ... raracterise par l'el roitesse du crane el par le developpenent de la region inférieure de la fare ".

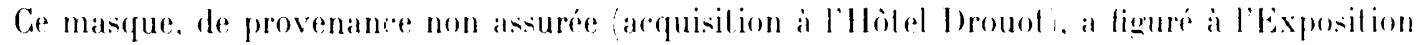
Iniverselle de 1889 et n'est ronnu que par la mention surcincte de s. Reinarls.

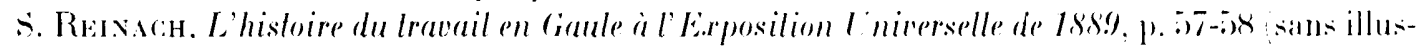
tration). R. IAxtmer, 1940, p. 109.

Cous avons tente de retrouver ce masque en prenant contact aver la famille de Lestrange: les membres de celle-ci nous ont reserve le meilleur accueil el nous avons pu savoir que la piece avait éte mise en vente a l'Hotel brouot le 8 mars 197. Les regles en vigueur en maliere de ventes publiques ne nous ont malheureusement pas permis dohtenir le nom du détenteur areluel de la pioce.

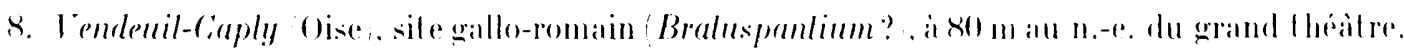

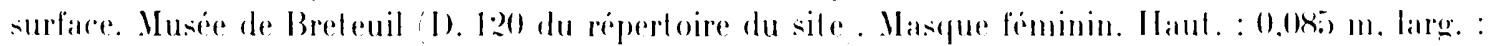

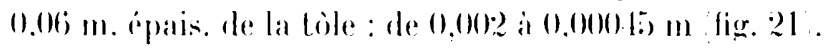

Le metal est découpe au pourlour de la piere ; la figuralion de la chevelure va justu au bord: aulour du visage existe une bande de medal de 8 a 10 mm de largeur. resté lisse. dans langelle on remarque des trous de rlous : trois. plus un a restiluer par symel rie sur le cole droil : un rinquieme

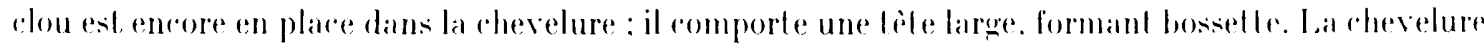
est figure par des reliefs sensiblement rectilignes, mais irréguliers : le nez est tres peu próminent.

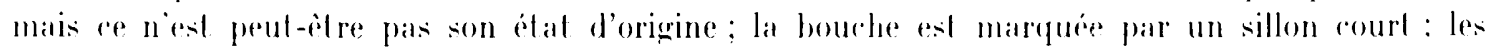
oreilles ne sont pas figurese. le soureil droit est tres marque par un relief incurve : le gandehe nest qu'à peine représente. "I es yeux sont figurés par des losanges proeminents que devait rentrer une

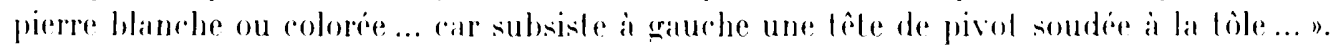

Renseignements aimablement foumis par le fouilleur de Vendeuil-Calply. II. (i. Mufour. upia prepare un travail densemble sur le site. dans lequel figurera re masque.

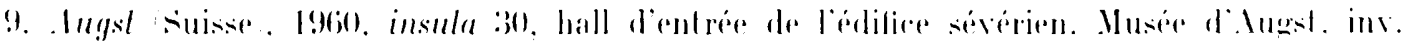

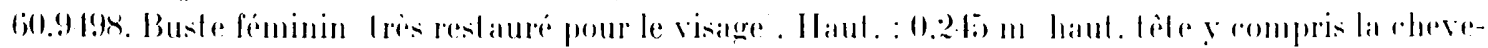

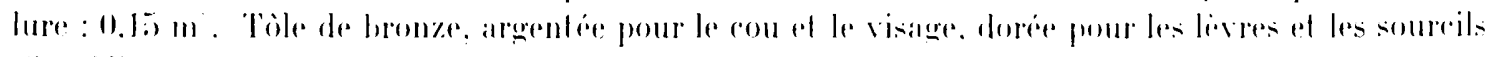
lic.. ?.). 
Cihevelure ondulée, opulente; cou paré d'un collier avec série de pendentifs, ciselé ; tunique à plus largese et plats : yeux figurés au repoussé dans le métal. Travail très influencé par l'art romain. leébut $11 I^{\mathrm{e}}$ s. (?).

Anne Kaupmax-Hesimax, Die römischen Bronzen der Schueiz, I. Augsl, Mayence, 1977, p. $85-86, n^{\circ} 89$, pl. 92.

10. Marnheim, Kr. Kirchheimbolanden (R.F. Allemagne/, découverte fortuite, 1904. Musée historique du Palatinat, spire, inv. 2000. Buste féminin (partie antérieure. Haut. : $0,208 \mathrm{~m}$ (larog. maximale de la tête : $0,091 \mathrm{~m})$.

La partie supérieure de la tète manque; on y restitue, selon la proposition de VI. II. Klumbacll, la coiffure des. Matronae de la vallée du Rhin. Cou trop épais, paré d'un collier auquel sont suspendus des globules et un croissant ; tunique à encolure en pointe, seins fortement marqués ; yeux entièrement figurés au repoussé dans le métal. Travail très inflencé par l'art romain. (Euvre considérée comme de la deuxieme moitié du if $\mathbf{e}$ s. au plus lòt.

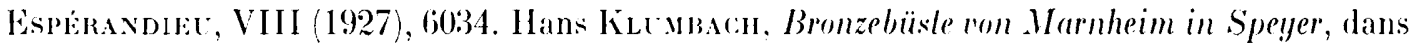

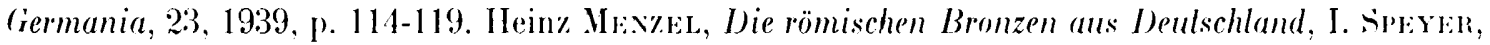
1. 25-26, pl. 24-25. F. Brakinik, 1965-1969, 2e partie, p. 84, fig. 41-42.

\section{b) Pièces partiellement en lôle de bronze.}

11. Bouray, canton de La Ferté-Alais (Essonne), dans la Juine (a l'ocrasion du curage de cette rivière, dans la partie de son cours traversant le parc du (hàteau de Mesnil-Voisinj), vers 1845. Musée des Anliquités nationales, Saint-(jermain-en-Laye, inv. 76jojl. Slatuette en tôle de bronze avec tôte en bronze coulé. Haut. totale: $0,42 \mathrm{~m}$; tête et cou : $0,21 \mathrm{~m}$.

Le corps el les jambes sont faits de deux pirces. l'une pour l'avant, l'aulre pour l'arriere. auxquelles s'ajoutaient des épaules soudées avec emboitement (la droite subsiste), sur lesquelles étaient soudés les bras (disparus). Les pieces avant et arrière, ajustées bord a bord, sont soudées avec recourrement des joints par des baguettes plates, ainsi que l'avait bien ru Héron de Villefosse (baguettes conservées entre cou et épaules, et le long du còté quarche du torse). Le " mode d'agrafage des joints de bronze pour l'assemblage des deux faces de la statuette " donné par R. Lantier (op. cil., p. 38, fig. 16) n'est pas conlirmé par l'examen de la pièce ; il aurait, pour nous, d'ailleurs été pratiquement impossible a réaliser. In seul oil, le galuche, est conservé : il est en pate de verre fondue d'une seule pièce, de deux couleurs : blanc pour la sclérotique, bleu foncé pour la prunelle; selon Héron de Villefosse, suivi par R. Lantier, il est " fixé á l'intérieur de la tète par un amalg̣ame de plomb fondu qui en recouvre entièrement le revers ». Cette indication n'est pas contrölable actuellement.

A. Hérox de Villefosse, 1913. R. Lantier, 19:34. J.-J. Hatt, 1966, p. 26 el fig. 1 couleur.

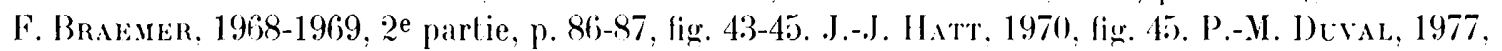
p. 188 et fig. 195 .

Une autre statuelte antique trourée en Gaule combinait un corps en tòle aver des parties en bronze coulé (tète, casque. bras, chaussures; : la grande statuette de déesse de Kerguilly en I)inéault (Finistère) : cf. René savocter, liallia. 31, 1973, p. 61-80. Les éléments en tiile n'ayant pu être conservés du fail de la corrosion, on ne la rite ici que pour mémoire.

12. La Croix-Saint-Ouen (Oise), vers 1873. Yusée des Intiquites nationales, saint-Germainen-Laye. inv. 27456/27453. Títe féminine constituée d'un masque en bronze coulé, fermé à l'arriere par une pièce en töle de bronze. Haut. : $0,156 \mathrm{~m}$ (fig. 2:3).

La pièce de töle est simplement appliquée sur la partie supérieure arriere du masque qui est lisse - et ajustée tant bien que mal sur les còtés. A. de Roucy indiquail, un agrafage " au moven d'œillets tournants" fixés sur la partie antérieure. Le systime paraît peu fonctionnel et cependant on ne remarque pas de trares de soudure. Cette piece de tole pend sous la nuque comme un roile court : elle n'est que sommairement façonnée. La chevelure comporte deux séries de boucles enroulíes 

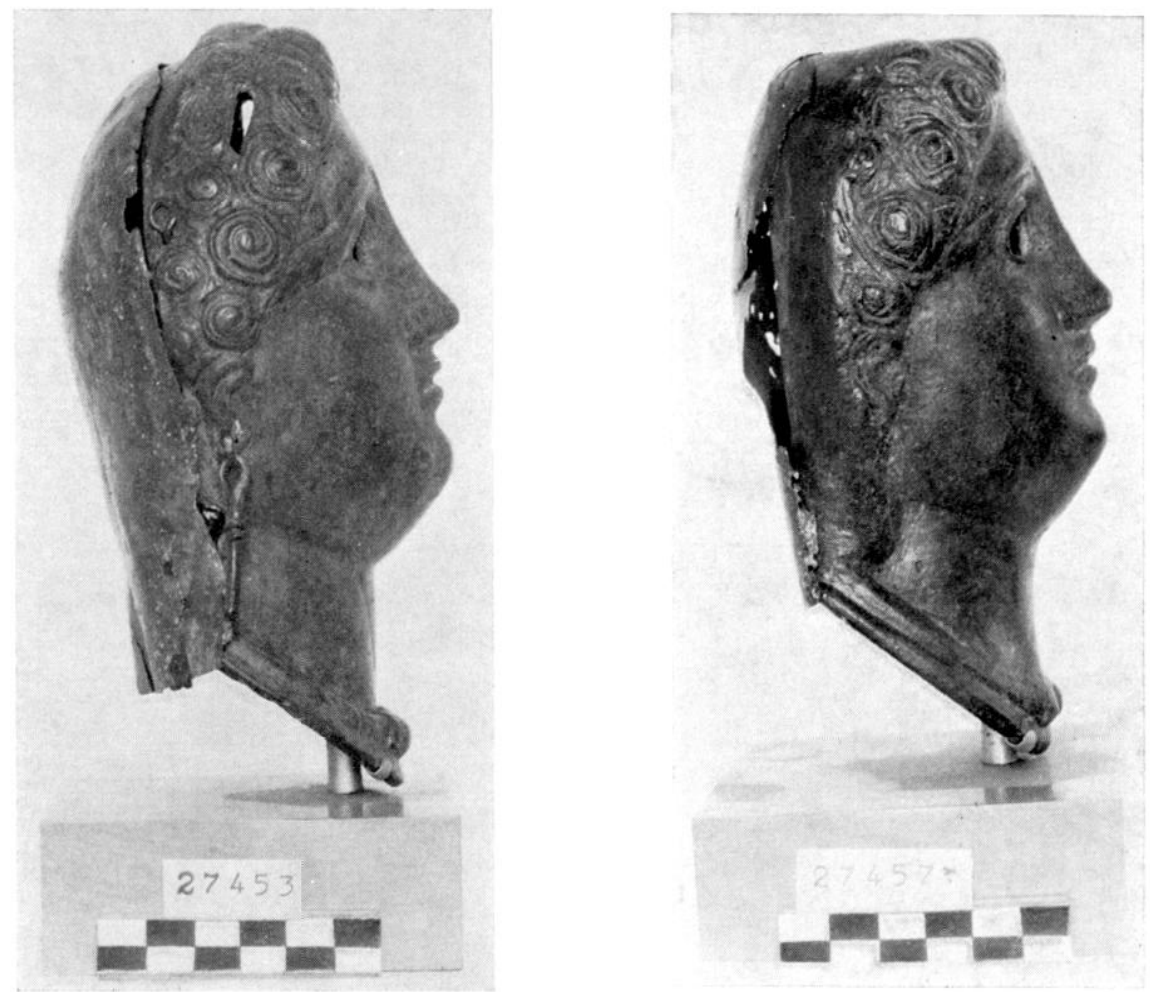

23, 24 lat Coix-sant-()nen. Tètes feminines.

en spirales, lraitées aver soin ; des bouctes d'oreilles allongées sont accrochées aux oreilles par des anneaux; on remarque sur le sommel du rrine deux fentes (pour la fixalion d'ailerons?) torques a exlremités bouletées au rou.

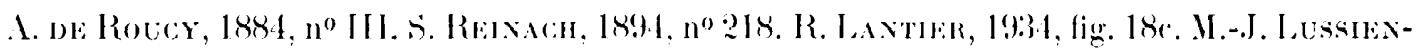
Malsoxineve, 1976, p. 112-11:3 el lig. 12-13.

13. La Groir Saint-Ouen (Oise), vers 187:). Musée des Intiquités nationales, saint-Germainen-laye, inv. 27.57/2745). Tèle féminine, de mème type que la précédente pour la lechnique, triss proche pour la plastique. Haut. 0,14 m (fig. 24).

Ce second exemplaire est manifestement la copie du premier qui a dù pour cela servir de matrice a un moule en argile; d'oi les différences de dimensions qui correspondent sensiblement au retrail de l'argile, sous reserve sans doule de quelques deformations; finition tris malhabile au burin des boucles de la chevelure.

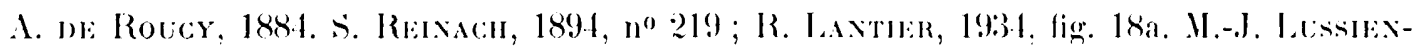
MAIsoxivive, 1976, p. 111-112 el fị. 10-11.

c) Masques en milanir aulres que le bronze.

14. Balh, somerset (Grande-Brelagnel. exout principal des Thermes, 1878. Roman Bath Museum, Bath. Masque masculin en élain. Haut. : $0.3: 3 \mathrm{~m}$; larg. : $1,24 \mathrm{~m}$ (lig. 25).

Visage sommairement fignué aver une coilfure stylisée : còtes longitudinales parallèles séparées du front par un relief, que l'on prendrait volontiers pour la figuration d'un bonnet. Yeux aux contours peu marqués. percés d'un trou rond "avec adjonclion de rondelles de métal fondu à l'arrière ". Oreilles tres petites. Nez rapporte, soudé avec bande de renfort a l'arriere. On remarque au pourtour du masque maintenant aplati des petils trous percés de l'intérieur six : 2 au sommet de la tête. 2 de chaque còté de la moilie inférieure du visage) pour le pasiage de clous de fixation sur un support de bois. 


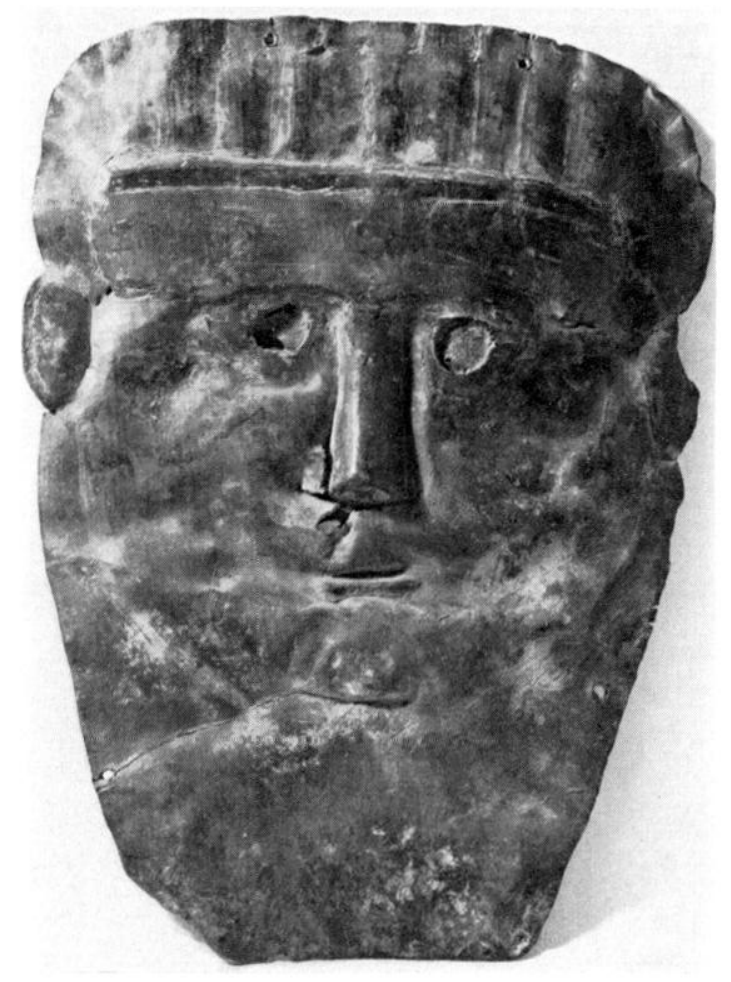

25) Bath. Masifue masculin. Copylight Inslitule of Ireharology, oxforil.

Charles Davs, Discoveries al Bath, dans Procerdings of the Society of . Inliquaries of London.

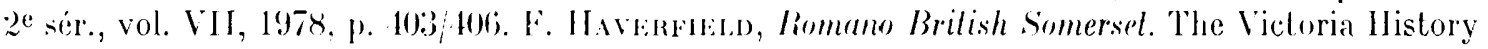

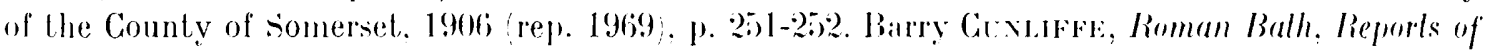
the Research Commitlee of the Antiquaries of London, XXIV, 1969, p. 6, no3.

15. Greal Chesterford. Essex Grande-Bretagne), site du temple, derouverte récente. Vusere de Cambribge. Masque masculin en argent, $1 / 2$ grandeur environ.

Divinite cellique, forlemenl barbue avec coiffure bouclée.

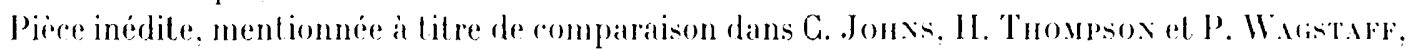
The Wincle, Cheshire, Hoard of Roman gold jewellery, dans The Antiquaries .Journal, I.X. 1980, 1, p. 5$)$

16, 17, 18. Mentionnons pour terminer trois pieces de comparaison intéressantes : les masques dits de Notre-Inane d'Allengon, sur lesquels une publication toute récente nous dispense de présenter des notices ici ; cf. Frangois Baratrs, Le lrésor d'argenterie gallo-romaine de . Votre-Isame d'Allençon (.aine-et-Loire), XIe suppl. i Callia, 1981 : masque en argent (haut. : 30,5 cm), calalogue, no 1 (pl. II-V); - a autre (haut. : $24.9 \mathrm{~cm}$; $\mathrm{n}^{\circ} 2$ (pl. VI-VII); ces deux masques sont considerés par II. Baralle comme "partie anterieure de tètes completes y ( $\mathrm{J}$. 30, n. 3), bien qu'il reconnaisse que la feuillure d'allente destinee a l'assemblage y soit "pratiquement inexistante" (1. 31. 1. 12): masque en fer (haut. : $16.8 \mathrm{cmi}$, no $5 \%$ (pl. XXXVI).

Cin autre masque en fer trouvé a Kamenné Kehronice. région de Kladno Bohème centrale.

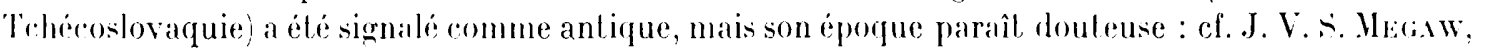
Art of the European Iron Age. Bath, 1970. no 172 (bib.). Werner Knawn, Eine "Keltische" Eisenmaslie ans Böhmen, dans Archänlogisches horrespondanzblalt. 1. 1971, 1. 39-40, pl. 9, 10.

$$
\text { I.-II. II. }
$$

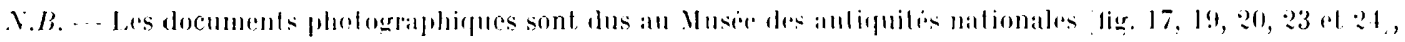

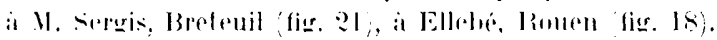




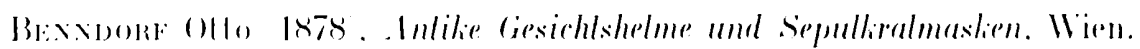

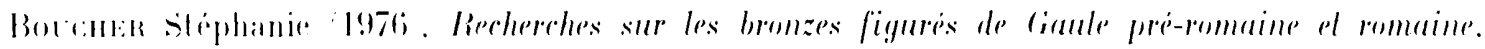
B.E.I...I.K. .).

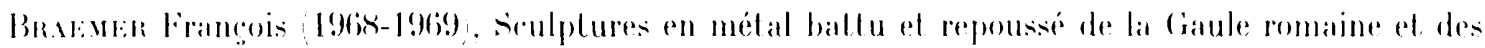

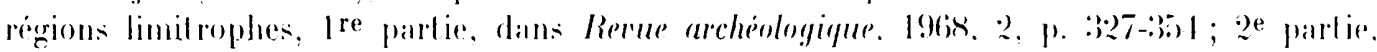
Rerue archeologique. 1969, 1. 1. $81-10 \%$.

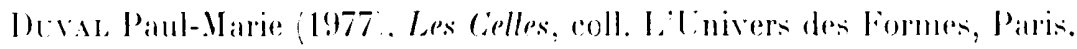

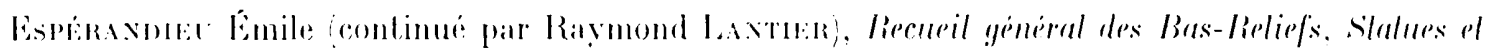
Busles de la fianle romaine, Paris lis vol.i.

(inkisan Mlbert! 1915). Les Cianlois. Paris.

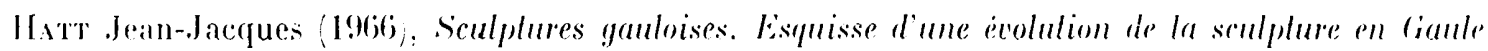
depuis le VIe s. anaml .J.-C. jusquian IVes. apres .J.-C.., J'aris.

HaTr .Jean-Jacques (1970). Celles el gallo-romains, coll. Archaelogia Mandi.

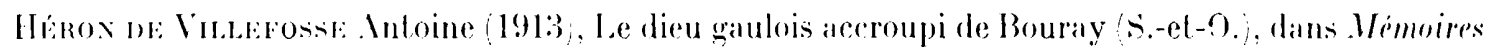
de la Suciele nalionale des . Intiquaires de France, I.XXII. P. 2.1.1-27.4.

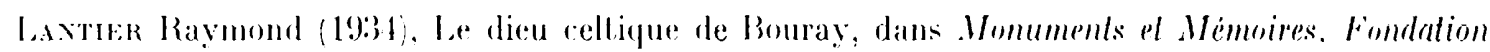
Eugene Piot, 1. 34, Paris, 1. 3i)-ix).

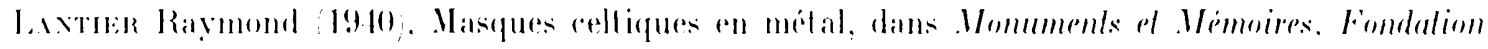
Eugene l'iol, 1. :37, laris, p. 1014-119.

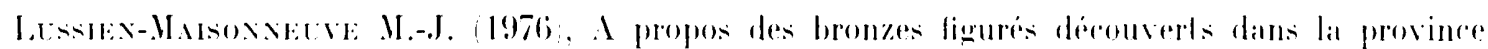
romaine de Belgique: quelques problemes de formes. de lypes el de lechniques, dans doles du IVe collonge internalional sur les bronzes anliques. I,yon. p. 109-11:).

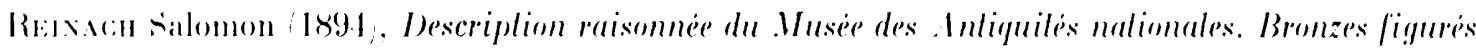
de la Giaule romaine, Paris.

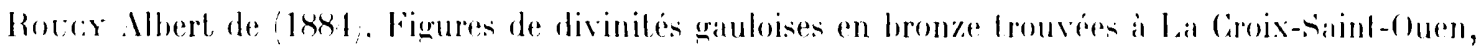

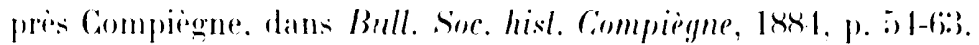

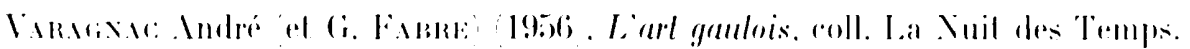

